ARTICLE

Received 27 Jan 2014 | Accepted 21 May 2014 | Published 24 Jun $2014 \quad$ DOl: 10.1038/ncomms5178

\title{
IP6K structure and the molecular determinants of catalytic specificity in an inositol phosphate kinase family
}

\author{
Huanchen Wang ${ }^{1}$, Eugene F. DeRose ${ }^{2}$, Robert E. London ${ }^{2} \&$ Stephen B. Shears ${ }^{1}$
}

Inositol trisphosphate kinases (IP3Ks) and inositol hexakisphosphate kinases (IP6Ks) each regulate specialized signalling activities by phosphorylating either $\operatorname{lns}_{3}$ or $\operatorname{InsP}_{6}$ respectively. The molecular basis for these different kinase activities can be illuminated by a structural description of IP6K. Here we describe the crystal structure of an Entamoeba histolytica hybrid IP6K/IP3K, an enzymatic parallel to a 'living fossil'. Through molecular modelling and mutagenesis, we extrapolated our findings to human IP6K2, which retains vestigial IP3K activity. Two structural elements, an $\alpha$-helical pair and a rare, two-turn $3_{10}$ helix, together forge a substrate-binding pocket with an open clamshell geometry. InsP $\mathrm{P}_{6}$ forms substantial contacts with both structural elements. Relative to $\operatorname{InsP}_{6}$, enzyme-bound $\operatorname{InsP}_{3}$ rotates $55^{\circ}$ closer to the $\alpha$-helices, which provide most of the protein's interactions with $\operatorname{InsP}_{3}$. These data reveal the molecular determinants of IP6K activity, and suggest an unusual evolutionary trajectory for a primordial kinase that could have favored efficient bifunctionality, before propagation of separate IP3Ks and IP6Ks.

\footnotetext{
${ }^{1}$ Inositol Signaling Group, National Institute of Environmental Health Sciences, National Institutes of Health, Research Triangle Park, North Carolina, NC 27709, USA. ${ }^{2}$ Nuclear Magnetic Resonance Group, National Institute of Environmental Health Sciences, National Institutes of Health, Research Triangle Park, North Carolina, NC 27709, USA. Correspondence and requests for materials should be addressed to S.B.S. (email: shears@niehs.nih.gov).
} 
$\mathrm{P}$ hosphate is a universal device for imposing specificity in cell signalling. The phosphate group's very bulk establishes geometric constraints on ligand-protein and proteinprotein interactions. In addition, the phosphate's negative charge at physiological $\mathrm{pH}$ bestows specificity through ionic and hydrogen bonding to only certain amino-acid residues. Signalling specificity is further enhanced through interactions that utilize multiple phosphates, such as those that are placed in various combinations around the six carbon inositol ring. Each of the resulting molecules_-inositol phosphates (InsPs) - have a distinct three-dimensional phosphate pattern that can encode unique signalling properties. Within this family of signalling molecules, there is a subgroup that possess functionally significant, 'highenergy' diphosphate groups: the inositol pyrophosphates (also known as diphosphoinositol polyphosphates) ${ }^{1,2}$. These molecules, particularly $\mathrm{InsP}_{7}$ and $\mathrm{InsP}_{8}$, are now viewed as being of fundamental importance in all eukaryotes ${ }^{2}$. Inositol pyrophosphates play pivotal roles in several aspects of cellular and organismic metabolic homeostasis ${ }^{1,3-7}$, and they regulate interferon transcription in response to viral infection ${ }^{8}$. Indeed, cell signalling by the inositol pyrophosphates is considered to be among the most evolutionarily ancient functions of the entire inositol phosphate family ${ }^{9}$. Thus, there is considerable interest in the kinases that synthesize $\operatorname{Ins}_{7}$ and $\mathrm{Ins}_{8}$.

For example, mammals express three isoforms of inositol hexakisphosphate kinases (IP6Ks) ${ }^{10,11}$ that each add a second phosphate group to a preexisting phosphate at the 5-position of the inositol ring. These kinases thereby convert $\mathrm{InsP}_{6}$ to 5 -PPIns $(1,2,3,4,6) \mathrm{P}_{5}\left(5-\operatorname{InsP}_{7}\right)^{12,13}$. The type 1 and type 2 isoforms (IP6K1 and IP6K2, respectively) have been the subject of a number of genetic studies with startling phenotypes. Silencing of IP6K1 in pancreatic $\beta$-cells inhibits insulin secretion ${ }^{4}$. Gene disruption of murine IP6K1 increases the insulin sensitivity of target tissues ${ }^{14}$, reduces spermatogenesis ${ }^{14}$ and compromises haemostasis ${ }^{15}$. Furthermore, in MEFs prepared from IP6K1 ${ }^{-/-}$ mice, DNA repair by homologous recombination is impaired ${ }^{16}$, the epigenetic program is altered ${ }^{17}$ and mitochondria are defective $^{3}$. A reduction in IP6K2 expression through an antisense strategy reduces apoptosis ${ }^{18}$, while IP6K2 $2^{-/-}$mice show increased susceptibility to carcinogen-induced squamous cell carcinoma ${ }^{19}$. As IP6Ks have so many important functions, the determination of their structures is a key research goal: such information illuminates catalytic mechanisms, regulatory processes and evolutionary relationships with other kinases, while also offering templates for the rational design of selective inhibitors as research tools or for therapeutic applications. However, IP6Ks have been stubbornly resistant to structural analysis for many years. Our goal has been to fill this significant void in our structural and molecular understanding, so as to further our insight into the entire inositol phosphate kinase family.

Entamoeba histolytica express an intriguing IP6K homologue (Genbank: XP_648490.2) that, secondary to its $\mathrm{InsP}_{6}$ kinase activity, also phosphorylates the $6-\mathrm{OH}$ of $\operatorname{Ins}(1,4,5) \mathrm{P}_{3}$ (ref. 20$)-$ an inositol phosphate multikinase (IPMK)-like activity ${ }^{10,21,22}$. IPMK itself is positionally promiscuous in that it is a 3-, 5- and 6kinase $^{23}$. Another nonspecific inositol phosphate kinase is ITPK1, which phosphorylates the 1-, 5- and 6-positions around the inositol ring 24 . Within the active sites of IPMK and ITPK1, the plane of the inositol rings in all of the alternate substrates are proposed to occupy the same spatial orientation, enabling each substrate to interact with a common set of protein contacts ${ }^{25-28}$. However, there has not previously been any direct structural confirmation of that hypothesis, because the published crystal structures of IPMK ${ }^{26,28}$ and ITPK1 ${ }^{27,29}$ lack bound substrate. We therefore considered that structural analysis of the IP6K from
E. histolytica could generate new ideas concerning specificity determinants of the positional promiscuity of inositol phosphate kinases.

IP6Ks are members of a wider inositol phosphate kinase family (Pfam PF03770) that includes IPMKs and inositol trisphosphate kinases (IP3Ks); these enzymes all share a PxxxDxKxG ('PDKG') catalytic motif ${ }^{10,21}$. Phylogenetic analysis 9 has led to the hypothesis that this kinase family arose from a primordial IP6K precursor. However, such an evolutionary pathway would be highly unusual, at least according to current thinking ${ }^{30}$. The issue of concern is that the original substrate $\left(\operatorname{InsP}_{6}\right)$ for the putative progenitor kinase is both larger and substantially more polar than the substrates for the descendant kinases: the $\mathrm{InsP}_{3}$ and $\mathrm{InsP}_{4}$ that are phosphorylated by IPMKs ${ }^{26,28}$ and the $\mathrm{InsP}_{3}$ that is specifically phosphorylated at the $3-\mathrm{OH}$ by $\mathrm{IP} 3 \mathrm{Ks}^{31,32}$. The traditional viewpoint is that improvements in the efficiency of catalysis of the smaller substrates $\left(\mathrm{InsP}_{3} / \mathrm{InsP}_{4}\right)$ would evolve through the compression of the active site $\mathrm{s}^{30}$. However, that would generally be expected to reduce activity against the larger InsP $\mathrm{P}_{6}$ molecule-a 'negative trade-off - that would impede organismic fitness and thereby select against the emergence of the independent $\mathrm{InsP}_{3} / \mathrm{InsP}_{4}$ kinase activities ${ }^{30}$. Such restrictions would seem inevitable if all substrates interacted with common structural elements. Nevertheless, the significant $\mathrm{Ins}_{3}$ kinase activity of $E$. histolytica $\mathrm{IP}^{2} \mathrm{~K}^{20}$ suggests it has somewhat overcome the constraints of negative trade-off; structural analysis could reveal how this was accomplished. We now describe several crystal complexes of the IP6K from E. histolytica, including those that contain either large $\left(\operatorname{Ins}(1,3,4,5,6) \mathrm{P}_{5} / \mathrm{InsP}_{6}\right)$ or small $\left(\operatorname{Ins}(1,4,5) \mathrm{P}_{3}\right)$ substrates. Furthermore, we extrapolate our findings to mammalian IP6Ks by site-directed mutagenesis of the human IP6K2. We describe two structural elements, an $\alpha$ helical pair and a rare, two-turn $3_{10}$ helix, that together form a substrate-binding pocket with an open clamshell geometry. $\operatorname{Ins}_{6}$ has substantial contacts with both structural elements. Relative to Ins $\mathrm{P}_{6}$, enzyme-bound $\mathrm{InsP}_{3}$ rotates $55^{\circ}$ closer to the $\alpha$-helices, which provide most of the protein's interactions with InsP $_{3}$. These data provide insight into the molecular determinants of both IP3Ks and IP6Ks, and suggest an unusual evolutionary trajectory for propagation of these separate kinases.

\section{Results}

Ins $(1,4,5) P_{3}$, InsP $_{5}$ and InsP $P_{6}$ phosphorylation by EhIP6KA. In our study, a recently characterized IP6K expressed by E. histolytica $^{20}$ (Genbank: XP_648490.2) is referred to as EhIP6KA, in order to distinguish it from two other gene products of E. histolytica that are currently also annotated as IP6Ks in Genbank. Highperformance liquid chromatography (HPLC) of the $\mathrm{InsP}_{7}$ synthesized by EhIP6KA (solid line, Fig. 1a) found it to co-elute with the 5 -InsP $\mathrm{P}_{7}$ produced by $\mathrm{HsIP}_{\mathrm{K} 2}$ (ref. 12) (dotted line, Fig. 1a). A previous study ${ }^{20}$ also concluded from HPLC that EhIP6KA synthesizes 5-InsP $\mathrm{P}_{7}$. Nevertheless, current HPLC methodology alone does not completely resolve all possible $\mathrm{InsP}_{7}$ isomers $^{33,34}$. Furthermore, there have been reports that amoeba contain atypical isomers of inositol pyrophosphates ${ }^{35}$. Considering that positional specificity is such a central feature of our study (see the Introduction), we employed nuclear magnetic resonance (NMR) for definitive characterization of the InsP $_{7}$ product $^{12,13}$.

To prepare sufficient quantities of pure $\operatorname{InsP}_{7}$ for $\mathrm{NMR}$ analysis, we adopted a strategy that has proved useful in the past ${ }^{12}$, namely, to analyse reaction mixtures (Fig. 1b). The ${ }^{1} \mathrm{H}$ chemical shifts of the unreacted Ins $\mathrm{P}_{6}$ and the product Ins $\mathrm{P}_{7}$ were assigned by comparison with reported InsP $_{6}$ chemical shifts ${ }^{13}$ and from an analysis of the $2 \mathrm{D}^{1} \mathrm{H}-{ }^{1} \mathrm{H}$ COSY spectrum of the reaction mixture (Supplementary Table 1). The proton resonances from 
a
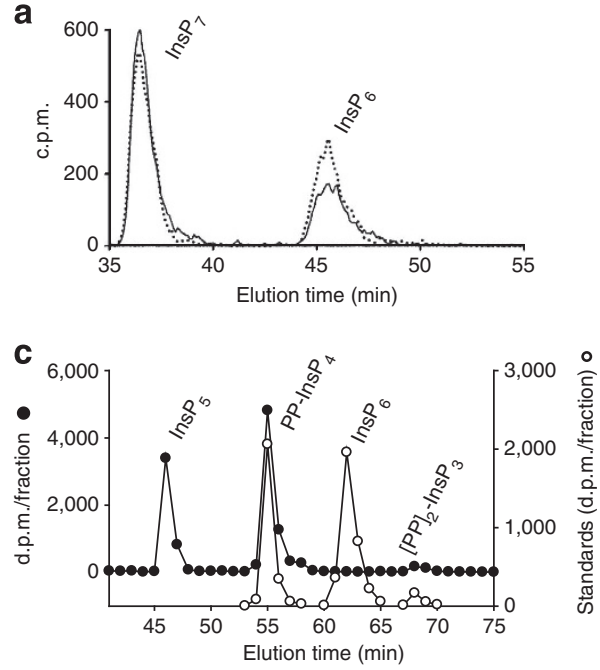

d

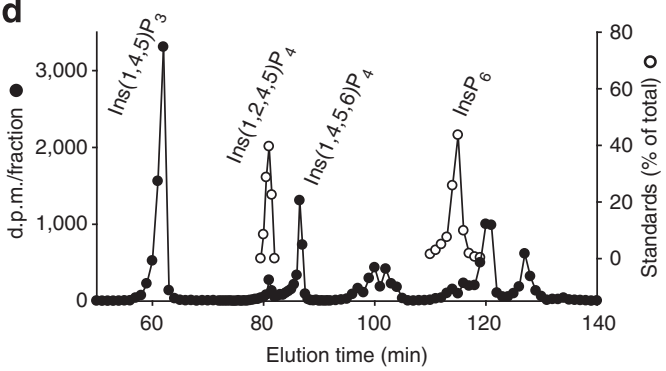

b

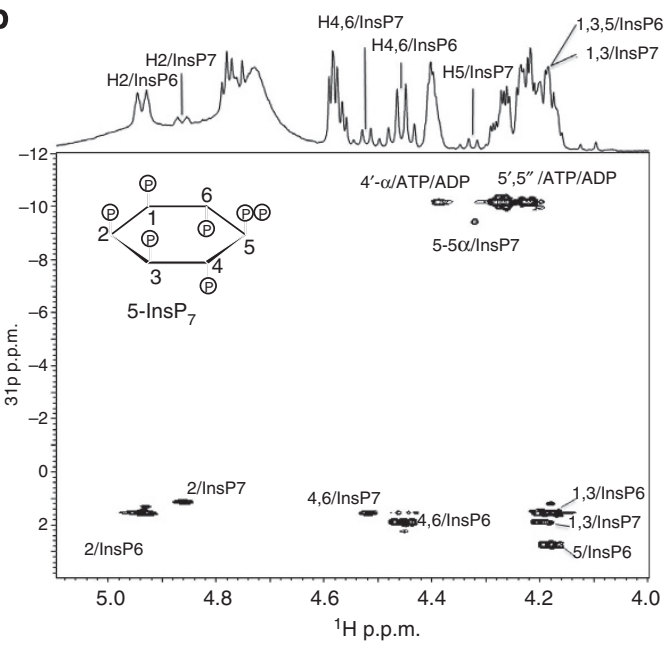

e

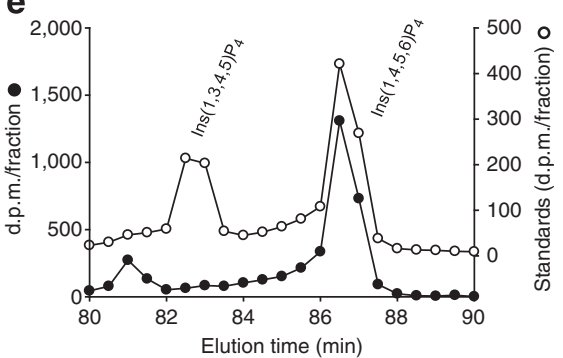

Figure 1 | HPLC and NMR analysis of the products of Ins(1,4,5)P $\mathbf{P}_{\mathbf{3}}$ and InsP $\mathbf{6}$ phosphorylation by EhIP6KA. (a) HPLC analysis (Partisphere SAX, Gradient 1; see Methods) of InsP 6 phosphorylation by either EhIP6KA (57 ng, 20 min; solid line) or HsIP6K2 (7.6 ng, 20 min; dotted line). (b) NMR analysis of the products of the reaction between InsP $\mathrm{P}_{6}$ and ATP catalysed by EhIP6KA; the figure depicts an overlay of the $1 \mathrm{D}{ }^{1} \mathrm{H}$ and $2 \mathrm{D} 1 \mathrm{H} /{ }^{31} \mathrm{P} H S Q \mathrm{C}$ spectra. The acquisition parameters are given under Methods. (c) HPLC analysis (Partisphere SAX, Gradient 2; see Methods) of the phosphorylation of $\sim 9,000$ d.p.m. $\left[{ }^{14} \mathrm{C}\right] \operatorname{Ins}(1,3,4,5,6) \mathrm{P}_{5}$ by EhIP6KA $\left(6 \mu \mathrm{g}, 20 \mathrm{~min}, 50 \mu\right.$; filled circles). Also shown are the elution of $\left[{ }^{3} \mathrm{H}\right]$-labelled internal standards of PP-InsP $\mathrm{P}_{4}$ and $[\mathrm{PP}]_{2^{-}}$ Ins $\mathrm{P}_{3}$, as well as InsP $\mathrm{P}_{6}$ (open circles). (d,e) depict representative HPLC assays ( $90 \mathrm{~min} ; 200 \mu \mathrm{l}$ ) that contained $\sim 10,000$ d.p.m. $\left[{ }^{3} \mathrm{H}\right] \mathrm{Ins}(1,4,5) \mathrm{P}_{3}$ plus $2 \mu \mathrm{g}$ EhIP6KA. After quenching and neutralization, products (filled circles) were analysed by Q100 SAX HPLC (Gradient 3); $\mathbf{d}$ includes the elution positions of standards of $\left[{ }^{3} \mathrm{H}\right] \operatorname{lns}(1,2,4,5) \mathrm{P}_{4}$ and $\left[{ }^{3} \mathrm{H}\right] \operatorname{lns} \mathrm{P}_{6}$ (open circles), determined in parallel HPLC runs; e zooms in on the Ins $\mathrm{P}_{4}$ region of the chromatograph; elution of internal $\left[{ }^{14} \mathrm{C}\right]$ standards of $\operatorname{Ins}(1,3,4,5) \mathrm{P}_{4}$ and $\operatorname{lns}(1,4,5,6) \mathrm{P}_{4}$ are also shown (open circles).

Ins $\mathrm{P}_{6}$ and Ins $_{7}$ are labelled in the $1 \mathrm{D}^{1} \mathrm{H}$ spectrum (Fig. $\left.1 \mathrm{~b}\right)$. The integral from the $\mathrm{InsP}_{6}$ protons in the $4 / 6$ positions is approximately three times larger than the corresponding integral arising from the PPIns $\mathrm{P}_{5}$ product, indicating that about $25 \%$ of the Ins $_{6}$ was phosphorylated. To verify the assignments and differentiate the $\mathrm{InsP}_{6}$ and $\mathrm{Ins}_{7}$ resonances, the $1 \mathrm{D}{ }^{1} \mathrm{H}$ and ${ }^{31} \mathrm{P}$ spectra were reacquired after spiking the sample with an additional $100 \mu \mathrm{l}$ of $5 \mathrm{mM} \mathrm{InsP}_{6}$. The major difference between the InsP $\mathrm{P}_{6}$ and $\mathrm{InsP}_{7}$ in the new ${ }^{1} \mathrm{H}$ spectrum is that the resonance from $\mathrm{H}-5$ is shifted to higher chemical shift and no longer overlaps the $\mathrm{H}-1,3$ resonances as it does in $\operatorname{InsP}_{6}$ (see also Supplementary Table 1). The remainder of the ${ }^{1} \mathrm{H}$ resonances exhibit less dramatic changes relative to the corresponding resonances in $\mathrm{InsP}_{6}$. The $\mathrm{H}-1,3$ and $\mathrm{H}-4,6$ resonances of $\mathrm{Ins}_{7}$ are equivalent due to the symmetry of molecule. These data are consistent with the site of phosphorylation being at the 5position. With the ${ }^{1} \mathrm{H}$ chemical shift assignments in hand, the ${ }^{31} \mathrm{P}$ chemical shifts of Ins $\mathrm{P}_{7}$ were assigned from a combined analysis of $2 \mathrm{D}{ }^{1} \mathrm{H}-{ }^{31} \mathrm{P}$ HSQC and ${ }^{31} \mathrm{P}-{ }^{31} \mathrm{P}$ COSY spectra (Supplementary Table 1). The HSQC spectrum correlates the ${ }^{1} \mathrm{H}$ shifts at each site to the ${ }^{31} \mathrm{P}$ shifts of the phosphate on the same carbon, and the COSY spectrum correlates the ${ }^{31} \mathrm{P}$ shifts of the two ${ }^{31} \mathrm{P}$ nuclei in the diphosphate moiety. The $\mathrm{H}-2, \mathrm{H}-1,3$ and $\mathrm{H}-4,6$ proton chemical shifts correlate to ${ }^{31} \mathrm{P}$ chemical shifts from the monophosphate groups in $\mathrm{InsP}_{7}$, and the $\mathrm{H}-5$ proton shift correlates to the ${ }^{31} \mathrm{P}$ chemical shift of the $\alpha$-phosphate of the only diphosphate group (Fig. 1b), so we conclude that the site of phosphorylation is the 5-position. Note the two other $\alpha$-phosphate resonances arise from the ADP product and from unreacted ATP (Fig. 1b). The $\beta$-phosphate chemical shift of InsP $\mathrm{P}_{7}$ is assigned from its correlation to the $\alpha$-phosphate chemical shift in the ${ }^{31} \mathrm{P}-{ }^{31} \mathrm{P}$ COSY spectrum. Thus, our NMR data reinforce the conclusion reached by HPLC that EhIP6KA, like mammalian IP6Ks, converts InsP 6 to 5 -Ins $\mathrm{P}_{7}$.

Mammalian IP6Ks also phosphorylate Ins $(1,3,4,5,6) \mathrm{P}_{5}$, yielding PP-InsP ${ }_{4}{ }^{12,36}$. We found that EhIP6KA likewise phosphorylates Ins $(1,3,4,5,6) \mathrm{P}_{5}$, and the major product co-elutes with a $\mathrm{PP}$ $\left[{ }^{3} \mathrm{H}\right] \mathrm{InsP}_{4}$ standard ${ }^{12,36}$; no InsP $\mathrm{P}_{6}$ was formed (Fig. 1c). A small amount of $[\mathrm{PP}]_{2}-\mathrm{InsP}_{3}{ }^{12,36}$ also accumulated (Fig. 1c). The first order rate constant for $\operatorname{Ins}(1,3,4,5,6) \mathrm{P}_{5}$ phosphorylation (mean \pm s.e.; $0.15 \pm 0.006 \mathrm{~s}^{-1} \mathrm{mg}^{-1}, \quad n=3$ ) is 40 -fold lower than that for $\operatorname{Ins}_{6}\left(6.1 \pm 0.64 \mathrm{~s}^{-1} \mathrm{mg}-1, n=3\right)$. The rate of phosphorylation of Ins $(1,4,5) \mathrm{P}_{3}$, another EhIP6K substrate ${ }^{20}$, was $0.028 \pm 0.005 \mathrm{~s}^{-1} \mathrm{mg}^{-1}(n=3)$, which is 220 -fold slower than that for $\operatorname{InsP}_{6}$. HPLC indicates that $\operatorname{Ins}(1,4,5,6) \mathrm{P}_{4}$ is the major Ins $\mathrm{P}_{4}$ product formed from $\operatorname{Ins}(1,4,5) \mathrm{P}_{3}$ (Fig. $\left.1 \mathrm{~d}, \mathrm{e}\right)^{20}$. We also observed the accumulation of an additional $\mathrm{InsP}_{4}$ isomer that coelutes with a standard of $\operatorname{Ins}(1,2,4,5) \mathrm{P}_{4}$ (Fig. 1d). The phosphorylation of an inositol phosphate at the 2-position has only previously been observed for IP $5 \mathrm{~K}^{26,37}$. We also confirmed 
that there were no pyrophosphorylated molecules associated with the $\mathrm{InsP}_{4}$ products, because these were not dephosphorylated upon their incubation with DIPP1 (Supplementary Fig. 1), an inositol pyrophosphate phosphatase that removes the $\beta$-phosphate from the diphosphate group ${ }^{36,38}$.

Overall structure of EhIP6KA. The structure of EhIP6KA (Fig. 2a-c; Table 1) was determined through two approaches. First, the structure of the fusion protein MBP-EhIP6KA (apoenzyme; residues $32-270$, space group P $2{ }_{1} 22_{1}$ ) was determined by a molecular replacement approach using MBP (1ez9) and IP3K $(1 \mathrm{w} 2 \mathrm{c})$ as search models. That information was then used for further molecular replacement in order to solve the structures of crystal complexes that bound ATP plus either $\operatorname{Ins}(1,4,5) \mathrm{P}_{3}$, Ins $(1,3,4,5,6) \mathrm{P}_{5}$ or InsP $_{6}$ (residues 27-270, space group $\mathrm{I}_{1} 22$ ), and a crystal of the apo-enzyme (residues 20-270, space group
$\mathrm{P} 2_{1}$ ). In the latter, the amino-terminal residues 20-29 were disordered.

For each asymmetric unit, our data are consistent with one molecule of MBP-EhIP6KA in space group P2 ${ }_{1} 2{ }_{1} 2_{1}$, one molecule of substrate-bound EhIP6KA in space group I4 22 and two molecules of apo-EhIP6KA in space group P2 $2_{1}$. The latter crystal structure was analysed with the protein interfaces, surfaces and assemblies service (https://www.ebi.ac.uk/pdbe/pisa/), which estimated an interface area of $814.7 \AA^{2}$ and total gained free energy upon interface formation of $-10.8 \mathrm{kcal} \mathrm{mol}^{-1}$. It was also assigned a complexation significance score of zero, indicating that the apo structure is a monomer. Furthermore, gel filtration indicates that apo-EhIP6KA is a monomer in solution.

Analysis of the overall fold of EhIP6KA (Fig. 2a,b) offers a description of some architectural elements that are shared with IPMKs and IP3Ks, while also revealing some molecular differences that may contribute to individual catalytic preferences.
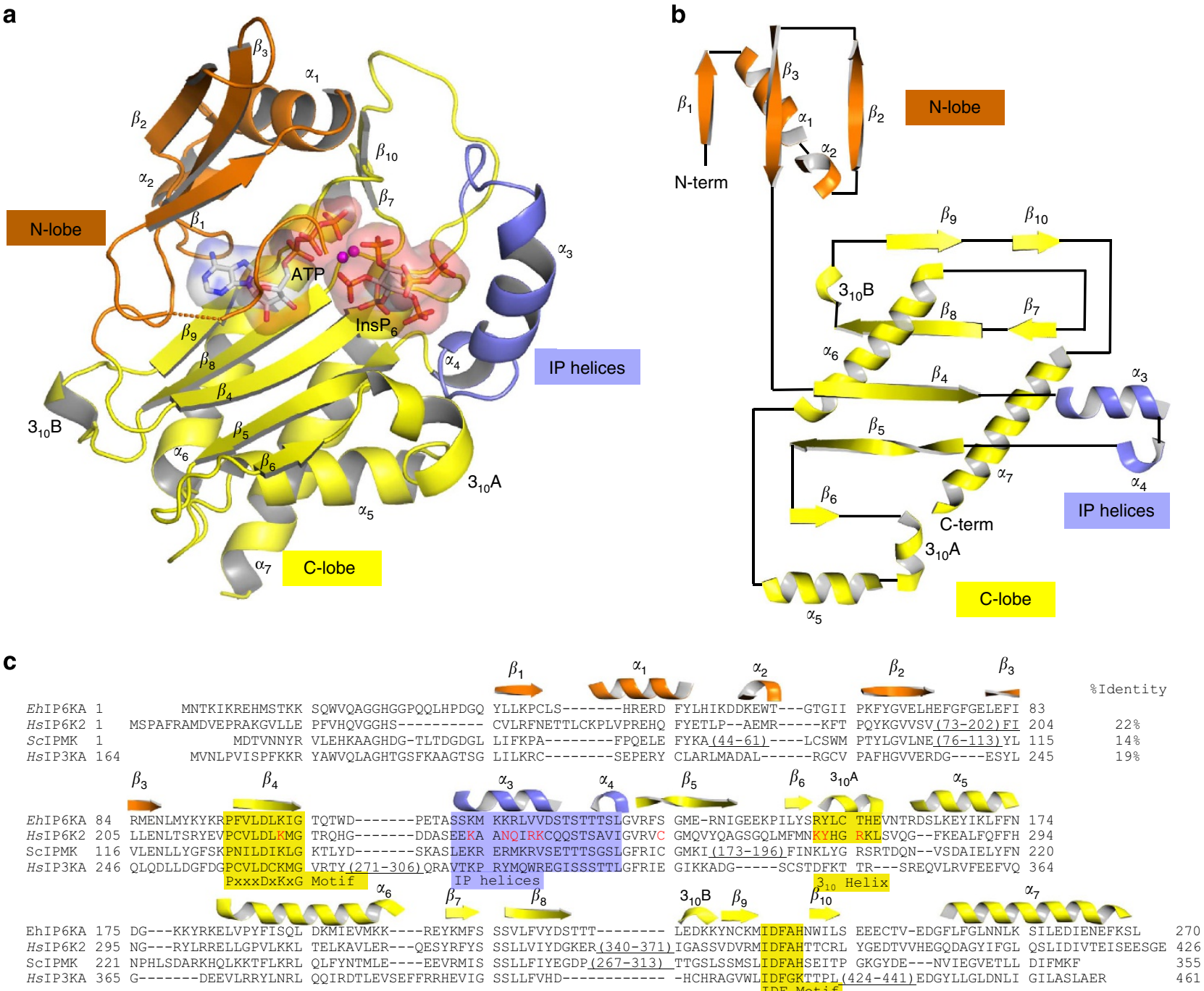

Figure 2 | Overall structure of EhIP6KA. (a) Ribbon-plot of EhIP6KA structure. ATP and InsP $\mathrm{P}_{6}$ are shown as sticks within a transparent surface. Two Mg atoms are depicted as magenta balls. (b) Topology diagram. (c) A manual alignment of amino-acid sequences (EhIP6KA, XP-648490.2; HsIP6K2, NP_057375.2; ScIPMK, NP_010458.3; HsIP3KA, NP_002211.1), guided by the structural elements that have been observed in crystal structures, and in the case of $H_{s} I P 6 K 2$, secondary structural predictions. Outside of the conserved catalytic core of the HsIP6K2 are two significant insertions that are omitted from the alignment. The first of these (residues 73-202) includes a specialized HSP90-binding domain ${ }^{54}$. The second insertion (residues $340-371$ ) includes a CK2-regulated, ubiquitination motif ${ }^{55}$. The secondary structural elements from EhIP6KA are depicted above its sequence and are color-coded orange for the N-lobe, yellow for the C-lobe and blue for the IP helices. Structural elements that directly participate in substrate interactions are highlighted by shading. Residues in HsIP6K2 that were selected for mutagenesis are coloured red. PDB codes for EhIP6KA are 4O4B, 4O4C, 4O4D, 4O4E, 4O4F. 


\begin{tabular}{|c|c|c|c|c|c|}
\hline PDB accession IDs & 404B & $404 \mathrm{C}$ & $404 \mathrm{D}$ & $404 \mathrm{E}$ & $404 \mathrm{~F}$ \\
\hline EhIP6KA residues & MBP-32-270 & $20-270$ & $27-270$ & $27-270$ & $27-270$ \\
\hline Ligand & Apo & Apo & $\operatorname{ATP}-\operatorname{Ins}(1,4,5) \mathrm{P}_{3}$ & $\operatorname{ATP}-\operatorname{Ins}(1,3,4,5,6) \mathrm{P}_{5}$ & ATP-InsP 6 \\
\hline \multicolumn{6}{|l|}{ Data collection } \\
\hline Space group & $\mathrm{P} 22_{1} 2_{1} 2_{1}$ & $\mathrm{P} 2_{1}$ & 14,22 & 14,22 & 14,22 \\
\hline $\begin{array}{l}\text { Cell dimensions } a, b, c(\AA), \beta \\
\left(^{\circ}\right)\end{array}$ & $\begin{array}{c}117.63,51.98 \\
117.33\end{array}$ & $\begin{array}{c}43.42,128.37,52.53 \\
\quad \beta=114.3^{\circ}\end{array}$ & $\begin{array}{c}102.74,102.74 \\
111.74\end{array}$ & $\begin{array}{c}\text { 103.00, } 103.00 \\
110.98\end{array}$ & $\begin{array}{c}102.23,102.23 \\
109.49\end{array}$ \\
\hline Resolution $(\AA)^{\star}$ & $50-1.8(1.83)$ & $50-1.9(1.93)$ & $50-2.1(2.14)$ & $50-1.9(1.93)$ & $50-1.7(1.73)$ \\
\hline Rsym $^{\star}$ & $0.057(0.457)$ & $0.078(0.235)$ & $0.086(0.551)$ & $0.049(0.527)$ & $0.053(0.540)$ \\
\hline$|/ \sigma|^{\star}$ & $39.6(3.1)$ & $25.0(3.6)$ & $29.1(3.4)$ & $42.9(2.6)$ & $56.7(2.4)$ \\
\hline Completeness $(\%)^{\star}$ & $99.4(99.4)$ & $98.6(93.3)$ & $99.4(100.0)$ & $99.3(93.9)$ & $96.4(71.6)$ \\
\hline Redundancy ${ }^{\star}$ & $5.0(4.8)$ & $3.7(3.0)$ & $6.7(6.2)$ & $8.1(6.3)$ & $9.8(5.2)$ \\
\hline \multicolumn{6}{|l|}{ Refinement } \\
\hline Resolution $(\AA)^{\star}$ & $1.8(1.84)$ & $2.2(2.27)$ & $2.1(2.16)$ & $1.9(1.95)$ & $1.7(1.74)$ \\
\hline No. reflections & 64,104 & 26,476 & 16,743 & 22,265 & 29,589 \\
\hline$R_{\text {work }}{ }^{\star}$ & $19.6(27.7)$ & $22.9(24.3)$ & $17.3(20.2)$ & $18.3(25.4)$ & $19.1(28.4)$ \\
\hline$R_{\text {free }}^{*}$ & $22.1(34.1)$ & $28.6(28.2)$ & $22.7(25.2)$ & $21.9(29.5)$ & $22.2(36.2)$ \\
\hline \multicolumn{6}{|l|}{ No. atoms } \\
\hline Protein & 5,010 & 4,039 & 2,080 & 2,084 & 2,075 \\
\hline Ligand/ion & & & 57 & 65 & 69 \\
\hline Solvent & 654 & 328 & 198 & 200 & 200 \\
\hline \multicolumn{6}{|l|}{$B$-factors $\left(\AA^{2}\right)$} \\
\hline Protein & 16.8 & 19.8 & 30.1 & 23.8 & 23.7 \\
\hline Ligand/ion & & & 52.6 & 36.9 & 39.3 \\
\hline Solvent & 47.1 & 29.7 & 46.3 & 41.5 & 42.1 \\
\hline \multicolumn{6}{|l|}{ R.m.s. deviations } \\
\hline Bond length $(\AA)$ & 0.006 & 0.007 & 0.012 & 0.011 & 0.01 \\
\hline Bond angle $\left(^{\circ}\right)$ & 1.10 & 1.18 & 1.71 & 1.73 & 1.83 \\
\hline
\end{tabular}

Among conserved elements, we identified domains in EhIP6KA that are similar to the so-called $\mathrm{N}$ - and C-domains that comprise the ATP-binding sites in both IPMK ${ }^{26,28}$ and $H s$ IP3 $\mathrm{KA}^{31,32}$. First, an N-terminal lobe in EhIP6KA can be designated from residues $28-91$, which consist of three antiparallel $\beta$-strands; the $\beta 1$ and $\beta 2$ strands are connected by two short helices $\alpha 1$ and $\alpha 2$. Second, we can designate a C-terminal lobe (residues 92-102 and 132270 ), which is an $\alpha+\beta$ fold with five, central antiparallel $\beta$-strands including $\beta 4-6$, as well as $\beta 8$ and $\beta 9$ (connected by a 3 -residue $3_{10}$ helix), a pair of small antiparallel $\beta$-strands ( $\beta 7$ and $\beta 10)$, and three $\alpha$-helices $(\alpha 5-\alpha 7)$. Also in the C-lobe of EhIP6KA, between the $\beta 6$ strand and the $\alpha 5$ helix, is an unusually long (6-residue), two-turn $3_{10}$ helix ( $3_{10} \mathrm{~A}$; Fig. $\left.2 \mathrm{a}\right)$ that is not present in either IPMK ${ }^{26,28}$ or $H s$ IP $3 \mathrm{KA}^{31,32}$. A $3_{10}$ helix of this length occurs relatively rarely because, being thinner and more tightly wound than classical $\alpha$-helices, it would usually be too unstable 39,40 . However, as we describe below, the highly specialized nature and orientation of the amino-acid side chains in this $3_{10}$ helix not only stabilize this structural element, but also make it functionally integral to substrate binding by EhIP6KA.

Description of the nucleotide-binding region of EhIP6KA. We observed that ATP is sandwiched between the $\mathrm{N}$ - and C-lobes of EhIP6KA (Fig. 2a); nucleotide binding did not alter protein conformation. Within a conserved IDF tripeptide (Fig. 2c) is Asp231, which coordinates with two Mg ions and makes polar contacts with the nucleotide phosphates (Fig. 3a,b). The orientation of the nucleotide in EhIP6KA is superimposable upon its position in the other kinases that share the PDKG motif, except for the more flexible $\gamma$-phosphate of ATP (Fig. 3c; Supplementary
Fig. 2), which may contribute to the unusually low affinity of IP6Ks for this nucleotide ${ }^{41}$. The adenosine moiety of ATP is docked in a hydrophobic pocket in EhIP6KA that is surrounded by residues Leu36, Pro65, Met85, Asn87, Met89 from the N-lobe and Leu211 and Ile230 from the C-lobe (Figs 3a and 4a). The $\mathrm{N}^{1}$ and $\mathrm{N}^{6}$ atoms of adenine are hydrogen bonded with the amide nitrogen and carbonyl oxygen of Leu88 and Glu86 respectively, which anchors the adenosine in the hydrophobic pocket (Figs 3a and 4a). The ATP-ribose group is loosely confined by several Van der Waals contacts with Val97, Asp99, Leu211 and Ile230. Lys38 forms two hydrogen bonds with oxygen atoms from the $\alpha$ - and $\beta$-phosphates (Figs 3a and 4a).

The molecular determinants of inositol phosphate binding. We have obtained crystal structures of EhIP6KA in complex with three different substrates: Ins $(1,4,5) \mathrm{P}_{3}$, Ins $(1,3,4,5,6) \mathrm{P}_{5}$ and $\operatorname{Ins}_{6}$ (Figs $4 \mathrm{a}, \mathrm{b}$ and $5 \mathrm{a}-\mathrm{d}$, Supplementary Fig. 3). Simulated annealing omit-maps and $2 F \mathrm{O}-F \mathrm{~F}$ maps show clear density of the substrate's inositol ring; the individual phosphate groups and their specific positions can each be identified (Supplementary Fig. 3).

The binding site for $\mathrm{InsP}_{6}$, which lies in a shallow depression in the enzyme's surface, can be likened to an 'open clamshell'. One jaw is represented by the IP helices, the other jaw comprises the $3_{10} \mathrm{~A}$ helix; note that neither HsIP3KA nor IPMK possess an equivalent to the $3_{10} \mathrm{~A}$ helix (Fig. 5e). The IP helices and the $3_{10}$ helix are not directly connected, but they approach within a sufficient proximity of each other to provide a metaphorical 'hinge' to the clamshell. Here, the 1- and 6-phosphates of InsP make contacts with Lys115, Lys118 and Arg119 in the $\alpha-3 / \alpha-4$ helical pair (Figs $4 \mathrm{~b}$ and $5 \mathrm{~d}$ ). Nevertheless, the plane of the 
a

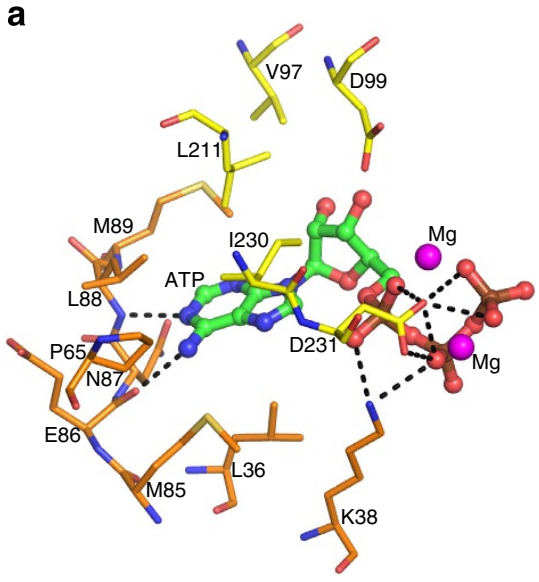

b
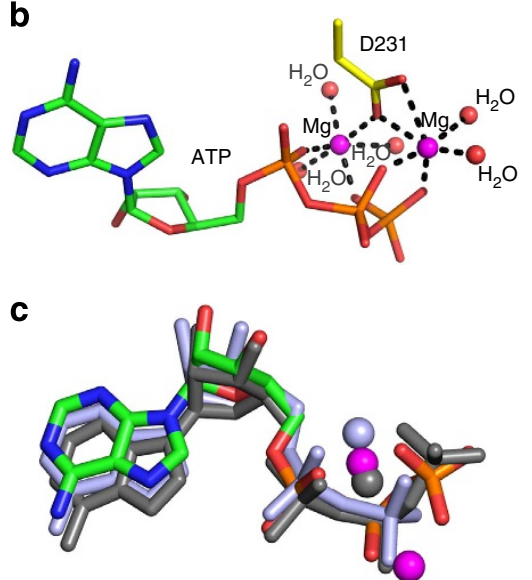

Figure 3 | Nucleotide binding by EhIP6KA. (a) ATP is depicted as a stick and ball model. Two Mg atoms are depicted as magenta spheres. Polar contacts are shown with dashed lines. Amino acids are shown as stick models. (b) Metal coordination. Two Mg atoms are depicted as magenta spheres. Water molecules are depicted as red spheres. The structure of ATP and Asp231 is shown as stick models. Polar contacts to coordinate with Mg atoms are shown with dashed lines. (c) The orientation of the EhIP6KA-bound nucleotide (green for carbon, red for oxygen, blue for nitrogen and orange for phosphorus atoms) and $\mathrm{Mg}$ atoms (magenta spheres) are superimposed upon that for HsIP3KA (grey stick represent AMPPNP (ATP analogue); grey spheres represent $\mathrm{Mg}$ ), and ScIPMK (light blue stick and spheres represent ADP and Mg).

a

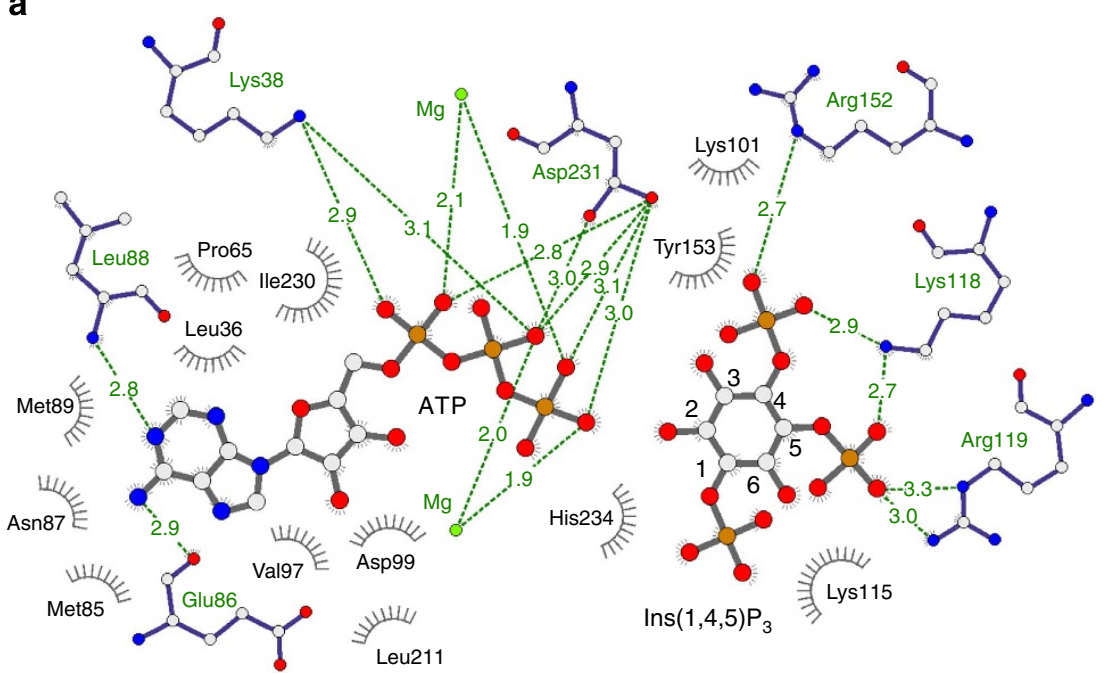

b

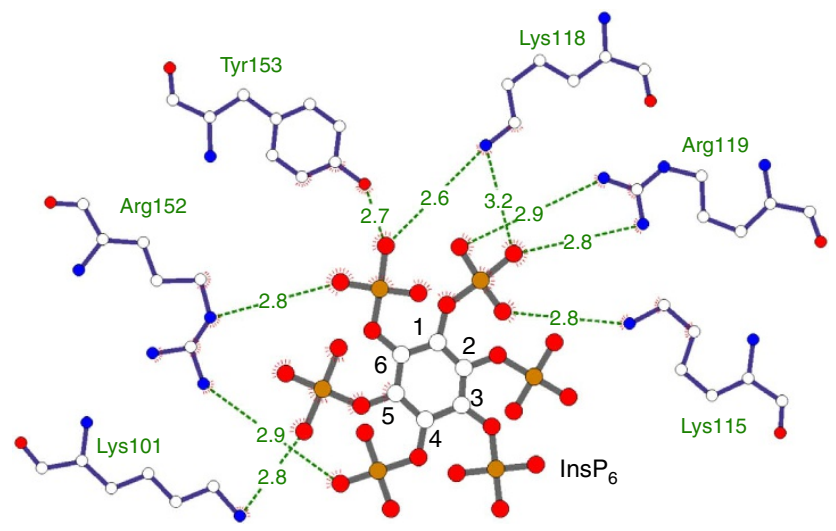

Figure 4 | Ligplots showing interactions of EhIP6KA with ATP and InsPs. Ligplots are shown for (a), ATP and Ins $(1,4,5) P_{3}$ and $(\mathbf{b})$, InsP $P_{6}$. Hydrogen bonds are shown in green dashed lines; bond distances are denoted in Angstroms. Residues that make hydrophobic interactions are depicted as grey eyelashes (cutoff distance is $3.9 \AA$ ). Atoms are shown white for carbon, red for oxygen, blue for nitrogen and orange for phosphorus. 
a

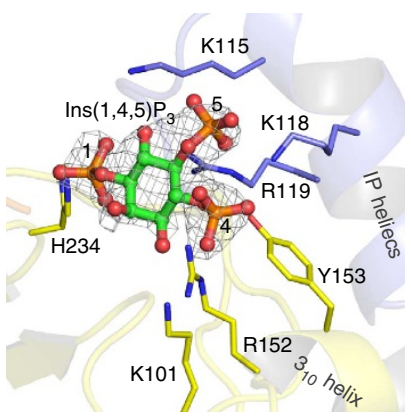

b

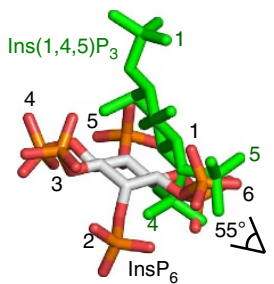

C

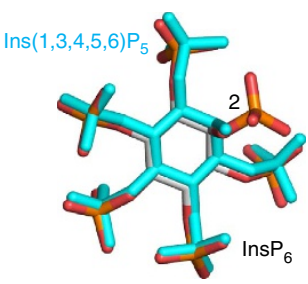

d

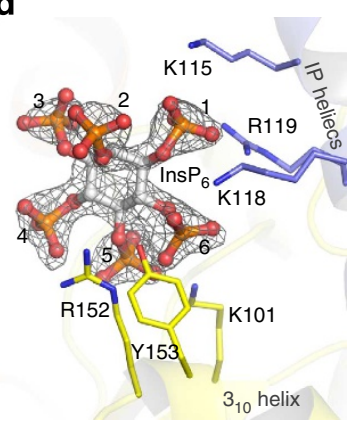

e

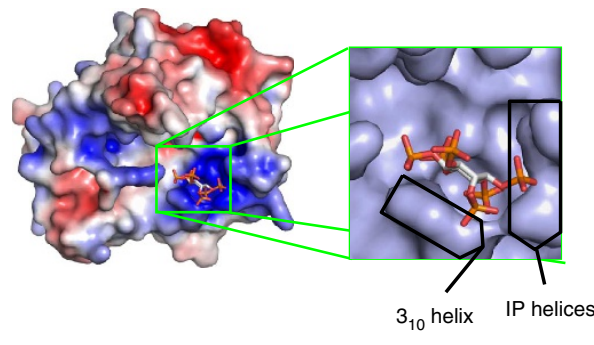

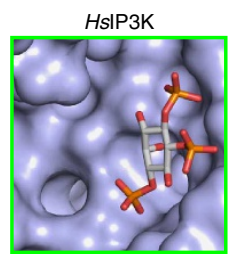

SCIPMK

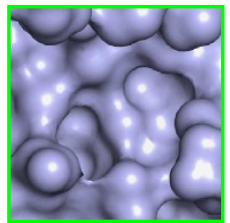

Figure 5 | Inositol phosphate-binding site for EhIP6KA. (a) Binding of Ins $(1,4,5) \mathrm{P}_{3}$ (stick and ball model; green for carbon, red for oxygen and orange for phosphorus atoms. The phosphate groups are numbered). The refined $2 F_{\mathrm{o}}-F_{\mathrm{c}}$ electron density map is contoured at $1.3 \sigma$. (b) Overlay of Ins $\mathrm{P}_{6}$ (grey stick model with orange and red phosphate groups) and $\operatorname{Ins}(1,4,5) \mathrm{P}_{3}$ (green stick). (c) Overlay of $\operatorname{Ins} \mathrm{P}_{6}$ and $\operatorname{Ins}(1,3,4,5,6) \mathrm{P}_{5}(\mathrm{cyan}$ stick). (d) Binding of InsP $_{6}$ (stick and ball model; green for carbon, red for oxygen and orange for phosphorus atoms). The phosphate groups are numbered. Amino acids are shown as stick models. The refined $2 F_{\mathrm{o}}-F_{\mathrm{c}}$ electron density map is contoured at $1.3 \sigma$. (e), Electrostatic surface plot with blue and red coloration to respectively indicate positive and negative electrostatic potentials at physiological $\mathrm{pH}$. In the magnified surface representation, the positions of the $3_{10}$ helix and IP helices are highlighted. Bound $\operatorname{Ins} \mathrm{P}_{6}$ is depicted as a stick model. Also shown are surface representation of $\operatorname{Ins}(1,4,5) \mathrm{P}_{3}$ in the active site of HsIP3K (data from ref. 32) and the active site of ScIPMK (data from ref. 26; crystals did not contain substrate).

inositol ring of Ins $\mathrm{P}_{6}$ runs parallel to the contour of the $3_{10} \mathrm{~A}$ helix (Fig. 5e), enabling the 4- and 6-phosphates to interact with Arg152 and Tyr153 (Figs 4b and 5d). These contacts appear to be stabilized by cation-pi interactions between Arg152 and Tyr153, which in turn are facilitated by the specific architecture of the $3_{10}$ helix (Supplementary Fig. 4).

Ins $(1,3,4,5,6) \mathrm{P}_{5}$ is also a substrate for EhIP6K (Fig. 1c,d). Indeed, Ins $(1,3,4,5,6) \mathrm{P}_{5}$ and $\operatorname{Ins}_{6}$ occupy a similar orientation within the active site (Fig. $5 \mathrm{c}$ ), indicating how both can be phosphorylated at the same position. IP6Ks can also phosphorylate $1-\mathrm{InsP}_{7}$ (ref. 13). Assuming that $\mathrm{InsP}_{6}$ and $1-\mathrm{InsP}_{7}$ also occupy similar orientations within the active site, molecular modelling indicates that the latter's $\beta$-phosphate projects into the bulk phase and should not greatly influence substrate binding.

While it is the 5-phosphate group on $\mathrm{InsP}_{6}$ that is diphosphorylated by EhIP6KA (Fig. 1b), it is either the 2- or the 6-OH of $\operatorname{Ins}(1,4,5) \mathrm{P}_{3}$ that is phosphorylated (Fig. 1d,e). Positional promiscuity in other inositol phosphate kinases has been rationalized by proposing alternative substrate-binding modes, in which the plane of the inositol ring occupies the same spatial orientation relative to the active site, enabling each substrate to share the same protein-contact points ${ }^{25-28}$. This is not the case for EhIP6KA. Instead, a unique adaptation of EhIP6KA lies in the nature of its contacts with $\operatorname{Ins}(1,4,5) \mathrm{P}_{3}$ that tilt the plane of the inositol ring by $55^{\circ}$ relative to that of $\operatorname{InsP}_{6}$ (Fig. $5 \mathrm{~b}$ ). Thus, near the clamshell hinge, the 5-phosphate of $\operatorname{Ins}(1,4,5) \mathrm{P}_{3}$ somewhat overlaps the space that would be occupied by the 1-phosphate of Ins $_{6}$ (Fig. 5b). However, at the open end of the clamshell, the 1phosphate of $\operatorname{Ins}(1,4,5) \mathrm{P}_{3}$ is positioned $7.5 \AA$ away from the location of the 3-phosphate of $\operatorname{InsP}_{6}$ (Fig. 5b). In fact, steric restrictions prevent $\mathrm{InsP}_{6}$ from occupying the same space as Ins $(1,4,5) \mathrm{P}_{3}$ in the substrate-binding pocket.

The $3_{10}$ helix makes only limited contact with $\operatorname{Ins}(1,4,5) \mathrm{P}_{3}$ : the 4-phosphate has just one hydrogen bond with Arg152 and there are weak Van der Waals interactions with Tyr153 (Figs 4a,5a). Instead, the plane of the inositol ring in $\operatorname{Ins}(1,4,5) \mathrm{P}_{3}$ is tilted closer to the IP helices, which are what this substrate mainly interacts with. Lys118 and Arg119 make contacts with the 4- and 5-phosphates of Ins $(1,4,5) \mathrm{P}_{3}$ (Figs $4 \mathrm{a}$ and 5a). The 1-phosphate, 6-hydroxyl and 5-phosphate of $\operatorname{Ins}(1,4,5) \mathrm{P}_{3}$ also have Van der Waals interactions with Lys115 (Fig. 4a). The 2-OH of Ins $(1,4,5) \mathrm{P}_{3}$ is positioned $3.7 \AA$ from the $\gamma$-phosphate of ATP (Supplementary Fig. 5), which is close enough to permit an inline phosphoryl-transfer reaction ${ }^{42}$. Indeed, our HPLC analysis revealed Ins $(1,2,4,5) \mathrm{P}_{4}$ to be a product of $\operatorname{Ins}(1,4,5) \mathrm{P}_{3}$ phosphorylation (Fig. 1d,e).

Furthermore, we remodelled the orientation of the inositol ring in enzyme-bound $\operatorname{Ins}(1,4,5) \mathrm{P}_{3}$, by flipping it $180^{\circ}$ across its $1 / 4$ axis, whereupon the $6-\mathrm{OH}$ of $\operatorname{Ins}(1,4,5) \mathrm{P}_{3}$ was then positioned $2.9 \AA$ from the $\gamma$-phosphate of ATP (Supplementary Fig. 5). This rationalizes the 6 -kinase activity against Ins $(1,4,5) \mathrm{P}_{3}$ by EhIP6KA (Fig. 1d,e). Thus, Ins $(1,4,5) \mathrm{P}_{3}$ can be held in the active site of EhIP6KA in two alternative, productive orientations, yielding either Ins $(1,2,4,5) \mathrm{P}_{4}$ or $\operatorname{Ins}(1,4,5,6) \mathrm{P}_{4}$ as products.

Another interesting observation is that, within the ligandbinding pocket of EhIP6KA, the orientation of the plane of the inositol ring of Ins $(1,4,5) \mathrm{P}_{3}$ shows a remarkable degree of spatial conservation with that for HsIP3KA (Fig. 5a,e, Supplementary 
Fig. 5); $;^{32}$ one inositol ring is simply flipped $180^{\circ}$ across its $2,3 / 5,6$ axis relative to the other so that, in $H s \mathrm{IP} 3 \mathrm{KA}$, the $3-\mathrm{OH}$ that is phosphorylated lies $4.6 \AA$ from the $\gamma$-phosphate of ATP (Supplementary Fig. 5), which is within the distance that permits an in-line, phospho-transfer reaction ${ }^{42}$. Thus, our data suggest that EhIP6KA be considered an enzymatic parallel to a 'living fossil' that illuminates the potential nature of a primordial $\mathrm{InsP}_{6} / \mathrm{InsP}_{3}$ kinase. In this putative protein, the open clamshell topology of the active site provides a partial diversification of specificity determinants for $\operatorname{Ins}(1,4,5) \mathrm{P}_{3}$ and $\operatorname{Ins} \mathrm{P}_{6}$, prior to its propagation into separate enzymes that could specialize in either of the two catalytic activities. We used mutagenesis to pursue this idea (see below).

Molecular modelling and mutagenesis of human IP6K2. So as to consolidate our structural work with EhIP6KA, and also to extrapolate it to mammalian IP6Ks, we turned to HsIP6K2 as a model for mutagenic studies. Interestingly, we found that $H s I P 6 K 2$ harbours a vestigial Ins $(1,4,5) \mathrm{P}_{3}$ kinase activity, some five orders of magnitude weaker than the Ins $\mathrm{P}_{6}$ activity (Fig. 6a). The products of Ins $(1,4,5) \mathrm{P}_{3}$ phosphorylation are $\operatorname{Ins}(1,3,4,5) \mathrm{P}_{4}$ and $\operatorname{Ins}(1,4,5,6) \mathrm{P}_{4}$ (Fig. 6b). Although the $\operatorname{Ins}(1,4,5) \mathrm{P}_{3}$ kinase activity was relatively low, it was sufficient to permit us to pursue the specificity determinants for each substrate.

For a positive control in the mutagenic experiments, we prepared a Lys222Ala mutant of HsIP6K2. This residue (equivalent to Lys101 in EhIP6KA; Figs 2c, $4 \mathrm{~b}$ and 5a,d), lies within the conserved PxxxDxKxG catalytic center (Fig. 2c). A HsIP6K2 construct in which this residue was mutated to Ala has previously been used as a kinase-impaired control when studying the effects of overexpression of wild-type enzyme in intact cells ${ }^{43}$. Nevertheless, to our knowledge, the degree to which this mutation inhibits recombinant enzyme activity has not previously been published. We found that the K222A mutant of HsIP6K2 exhibits negligible catalytic activity (Fig. 6a).

Our structural analysis of EhIP6KA indicates that Lys115 in the IP helices of EhIP6KA has multiple interactions with both substrates (Figs 4 and 5). We mutated the corresponding Lys236 in HsIP6K2 (Fig. 2c) to Ala; catalytic activity against both substrates was strongly reduced (Fig. 6a). Lys118 and Arg119 are two other residues in the IP helices of EhIP6KA that make contact with both substrates (Figs 4 and 5). These residues are not precisely replicated in $H s \mathrm{IP} 6 \mathrm{~K} 2$, according to both our sequence alignments (Fig. 2c) and our molecular model of the mammalian kinase (Supplementary Fig. 6A). Instead, our modelling indicates that Lys243 in HsIP6K2 has functionally significant interactions with the 6-phosphate of Ins $_{6}$ (Supplementary Fig. 6A). Indeed, an Lys243Ala mutation in $H_{s}$ IP6K2 decreased $\mathrm{InsP}_{6}$ kinase activity 600-fold (Fig. 6a) without affecting $\operatorname{Ins}(1,4,5) \mathrm{P}_{3}$ phosphorylation. These data speak to the specialization of the $\operatorname{InsP}_{6}$ kinase activity of $H s$ IP6K2.

We next used mutagenesis to test our hypothesis drawn from structural data that the $3{ }_{10} \mathrm{~A}$ helix in IP6Ks is particularly important for binding Ins $\mathrm{P}_{6}$. Arg152 and Tyr153 in the $3_{10} \mathrm{~A}$ helix of EhIP6KA align with Lys274 and Tyr275 in the equivalent region of HsIP6K2 (Fig. 2c). We found that Lys274Ala and Tyr275Ala mutants of HsIP6K2 exhibited a decrease in $\mathrm{InsP}_{6}$ kinase activities of 55- and 8-fold, respectively; the fact that these two mutations did not affect Ins $(1,4,5) \mathrm{P}_{3}$ kinase activities (Fig. 6a) confirms our conclusion that they play only a minor role in binding Ins $(1,4,5) \mathrm{P}_{3}$. Interestingly, the $3_{10} \mathrm{~A}$ helix of $H s I P 6 \mathrm{~K} 2$ contains an Arg residue at position 278 for which there is no equivalent in EhIP6KA (Fig. 2c). Molecular modelling of HsIP6K2 suggests Arg278 might contribute positive charge to the substrate-binding pocket, and/or stabilize the $3_{10}$ helix a

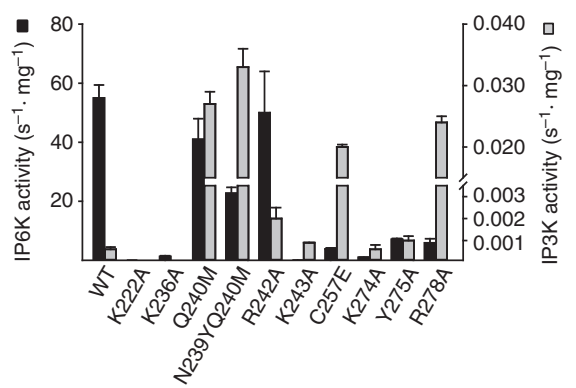

b

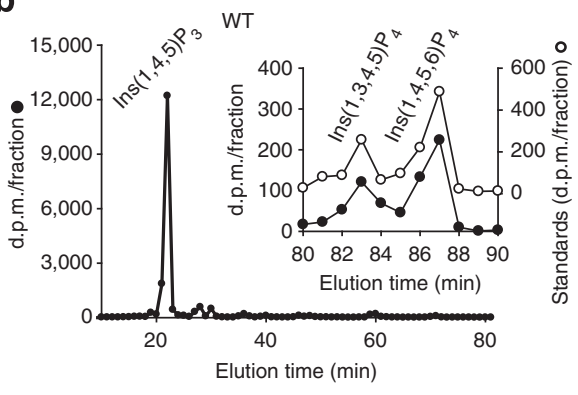

c

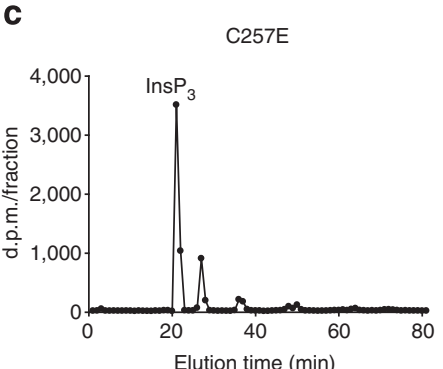

d

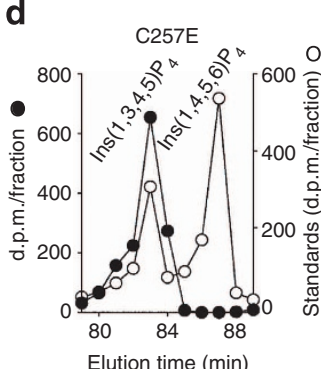

e

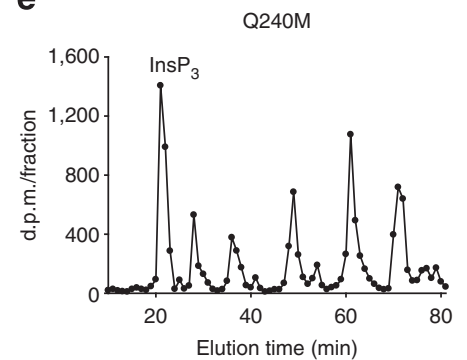

Figure 6 | HPLC analysis of the kinase activities of wild-type and mutant IP6Ks. (a) InsP 6 kinase (black bars) and Ins $(1,4,5) P_{3}$ kinase $(g r e y$ bars) activities of wild-type HsIP6K2 and the indicated mutants (means \pm s.e., $n \geq 3$ ). (b) Shows representative HPLC analysis (Partisphere SAX; Gradient 2) of Ins $(1,4,5) \mathrm{P}_{3}$ kinase activities of wild-type HsIP6K2 $(8 \mu \mathrm{g}, 7 \mathrm{~h})$. The inset to $\mathbf{b}$ shows HPLC analysis (Q100 SAX; Gradient 3 ) of the InsP 4 products formed by the wild-type enzyme (closed circles) together with the elution of internal standards of $\left[{ }^{14} \mathrm{C}\right]-\operatorname{Ins}(1,3,4,5) \mathrm{P}_{4}$ and $\left[{ }^{14} \mathrm{C}\right]-\operatorname{Ins}(1,4,5,6) \mathrm{P}_{4}($ open circles). (c) Shows a representative HPLC analysis (Partisphere SAX; Gradient 2) of Ins (1,4,5)P 3 kinase activity of a Cys257Glu mutant of HsIP6K2 $(5 \mu \mathrm{g}, 1 \mathrm{~h}$ ). (d) Shows a representative HPLC analysis (Q100 SAX; Gradient 3) of the InsP 4 products formed by a Cys257Glu mutant of HsIP6K2 (5 $\mu$, $45 \mathrm{~min}$ ). (e) Shows a representative HPLC analysis of Ins $(1,4,5) \mathrm{P}_{3}$ kinase activity of a Gln240Met mutant of HsIP6K2 (11 $\mu$, $\left.7 \mathrm{~h}\right)$. WT, wild type. 
through cation-pi interactions with Tyr274 (Supplementary Fig. 6B). Consistent with these ideas, an Arg278Ala mutant of $H s$ IP6K2 exhibited a ninefold reduction in $\mathrm{InsP}_{6}$ kinase activity compared with wild-type enzyme (Fig. 6a). Interestingly, the Arg278Ala mutant also showed a dramatic increase in Ins $(1,4,5) \mathrm{P}_{3}$ kinase activity (Fig. 6a). It is possible Arg278 has a negative impact on $\operatorname{Ins}(1,4,5) \mathrm{P}_{3}$ phosphorylation by attracting it into a nonproductive orientation.

The electronegative Glu333 in the C-lobe of HsIP3KA ${ }^{32}$ (Supplementary Fig. 6C) is replaced by Ser136 in EhIP6KA and Cys257 in HsIP6K2 (Fig. 2c). Structural modelling of this region of HsIP6K2 (Supplementary Fig. 6B,C) indicates a Cys257Glu replacement in $\mathrm{HsIP} 6 \mathrm{~K} 2$ would cause electrostatic repulsion of Ins $\mathrm{P}_{6}$ but not Ins $(1,4,5) \mathrm{P}_{3}$. Indeed, we prepared a Cys $257 \mathrm{Glu}$ mutant of $H_{s} \mathrm{IP} 6 \mathrm{~K} 2$ and it showed 14-fold lower InsP $\mathrm{P}_{6}$ kinase activity than wild-type enzyme (Fig. 6a). Moreover, this mutant showed a 33-fold increase in the rate of phosphorylation of Ins $(1,4,5) \mathrm{P}_{3}$ (Fig. 6a), specifically at the $3-\mathrm{OH}$ group (Fig. 6c,d). These results indicate the importance of Glu333 in the evolution of catalytic specificity of $H s$ IP3KA.

Finally, a hydrophobic patch in the IP helices in HsIP3KA and ScIPMK (Tyr315/Met316 in HsIP3KA, Met151 in ScIPMK; Fig. 2c), against which the inositol ring is proposed to rest, is hypothesized to enhance $\operatorname{Ins}(1,4,5) \mathrm{P}_{3}$ binding ${ }^{32}$. This hydrophobic patch is missing from both EhIP6KA and HsIP6K2 (Fig. 2c). We introduced HsIP3KA-like hydrophobic residues into the corresponding region of the IP helices of HsIP6K2 by preparing a single Gln240Met mutant and a tandem Asn239Tyr/Gln240Met mutant. These two mutant enzymes both exhibited a 50 -fold increase in the rate of $\operatorname{Ins}(1,4,5) \mathrm{P}_{3}$ phosphorylation (Fig. 6a). Moreover, the variety of products that were formed was significantly increased (compare Fig. 6b and e), perhaps by favoring multiple ligand-binding modes. Arg242Ala is another mutation that increases the hydrophobicity of the IP helices; this elicited a threefold increase in $\operatorname{Ins}(1,4,5) \mathrm{P}_{3}$ phosphorylation (Fig. 6a). Significantly, $\operatorname{InsP}_{6}$ kinase activity of HsIP6K2 was not substantially affected by these mutations to Asn239, Gln240 or Arg242 (Fig. 6a). These mutagenic data confirm the structural information that indicate $\mathrm{InsP}_{6}$ and Ins $(1,4,5) \mathrm{P}_{3}$ have non-overlapping orientations in the substratebinding site. Ins $\mathrm{P}_{6}$ cannot interact with the synthetic hydrophobic patch since the plane of its inositol ring is tilted away from the plane of the IP helices, unlike that of $\operatorname{Ins}(1,4,5) \mathrm{P}_{3}$ (Fig. 5b,e). These mutagenic experiments also offer evolutionary insight by providing proof-of-principle of the nature of mutations to a progenitor kinase that could have increased $\operatorname{Ins}(1,4,5) \mathrm{P}_{3}$ kinase activity without negative trade-off from a compromised $\mathrm{InsP}_{6}$ kinase activity.

\section{Discussion}

In this study, we describe the crystal structure of a bifunctional IP6K/IP3K from E. histoloytica (EhIP6KA), and we extrapolate our findings to a human IP6K with mutagenic and biochemical experiments. The most important new ideas that we draw from this information are as follows: first, the geometry of the substrate-binding site is revealed to exhibit a relatively spacious, open clamshell geometry; one jaw is represented by a pair of $\alpha$ helices, the other jaw is an unusually long $3_{10}$ helix. Second, we show that $\mathrm{Ins}_{3}$ and $\mathrm{Ins}_{6}$ have non-overlapping orientations within the substrate pocket. Thus, relatively large InsPs (Ins $\left.(1,3,4,5,6) \mathrm{P}_{5} / \operatorname{Ins}_{6}\right)$ form contacts with both the $\alpha$-helices and the $3_{10}$ helix. In contrast, the smaller Ins $\mathrm{P}_{3}$ molecule is rotated $55^{\circ}$ closer to the $\alpha$-helices; the latter provide most of the protein's interactions with $\mathrm{Ins}_{3}$. Third, we describe an unusual evolutionary trajectory that could have favored efficient bifunctionality in a primordial kinase, prior to propagation of separate, dedicated IP3Ks and IP6Ks.

Previous ideas concerning how specialized enzymes diverged from promiscuous progenitors are based on the paradigm that the native catalytic activity should generally involve a substrate that is smaller than the emerging substrate, without a change in its degree of polarity ${ }^{30}$. For the putative primordial ${\text { IP } 6 K^{9}}^{9}$, the original, preferred substrate $\left(\mathrm{Ins}_{6}\right)$ would have been both larger and substantially more polar than the $\mathrm{InsP}_{3}$ substrates for the emerging kinases (IPMK and IP3K). Usually, the evolution of increased catalytic activity against smaller substrates depends upon compression of the active site ${ }^{30}$. That development would be expected to reduce activity against the larger Ins $\mathrm{P}_{6}$ moleculea 'negative trade-off - that would impede organismic fitness and thereby select against the emergence of the $\mathrm{InsP}_{3} / \mathrm{InsP}_{4}$ kinase activities $^{30}$. However, our substrate-bound structures of EhIP6KA uncover a partial separation of the binding sites for $\operatorname{Ins}(1,4,5) \mathrm{P}_{3}$ and InsP $_{6}$. It is because of these non-overlapping substrate orientations that the insertion of a hydrophobic patch into the $\alpha$ helices can enhance IP3K activity without affecting IP6K activity: an avoidance of negative trade-off that would have favored efficient bifunctionality. It appears that E. histolytica may be a particularly appropriate model for gaining insight into evolution of a hybrid IP6K/IP3K, since current annotations of this organism's genome indicate that it does not encode a specialized Ins $(1,4,5) \mathrm{P}_{3}$ 3-kinase. Thus, we conclude that EhIP6KA is the enzymatic equivalent of a 'living fossil' that is suggestive of the nature of a primordial IP6K prior to gene duplication. After the latter event had occurred, it would appear that evolutionary gain of function of $\operatorname{Ins}(1,4,5) \mathrm{P}_{3}$ phosphorylation would then have involved atrophy of the $3_{10}$ helix and consolidation of the role of the IP helices in substrate binding (Fig. 5e). In HsIP3KA, the IP helices have been replaced with a distinct, highly structured 63-residue inositol-phosphate-binding domain: four helices with greater structural constraints that limit substrate selectivity to $\operatorname{Ins}(1,4,5) \mathrm{P}_{3}$ alone ${ }^{31,32}$. The $3_{10}$ helix has also been lost from IPMK (Fig. 5e), but the substrate-binding pocket remains relatively spacious, thereby retaining a degree of positional promiscuity.

Each of the inositol phosphate kinases that share the PDKG motif-IP6Ks, IPMKs and IP3Ks-are specialized to synthesize unique InsPs with differing biological actions. Our molecular understanding of these catalytic specializations has been incomplete, since among these proteins, only $H s$ IP3KA has previously been co-crystallized with substrate ${ }^{32}$. In contrast, the published crystal structures of IPMK ${ }^{26,28}$ lacked bound substrate. Thus, our atomic level description of a substrate-bound IP6K fills a significant void in our structural and molecular understanding of the determinants of catalytic activity in the entire PDKG motif kinase family. This information is also relevant to IP5Kpreviously thought to be the only inositol phosphate kinase capable of phosphorylating the 2-OH. Nevertheless, in crystals of substrate-bound IP5K, the orientation of the axial $2-\mathrm{OH}$ of Ins $(1,3,4,5,6) \mathrm{P}_{5}$, relative to ATP, is very similar to the orientation of the equatorial 3-OH of Ins $(1,4,5) \mathrm{P}_{3}$, relative to ATP, in crystals of HsIP3KA $\mathrm{KA}^{44}$. Furthermore, the current study shows that the inositol ring of $\operatorname{Ins}(1,4,5) \mathrm{P}_{3}$ occupies very similar relative positions in the active sites of EhIP6KA and HsIP3KA (Fig. 5; Supplementary Fig. 5). This spatial conservation of substrate binding between these different inositol phosphate kinases is also matched by spatial conservation of some key active-site residues ${ }^{45}$. Such observations help to rationalize our observation that EhIP6KA phosphorylates $\operatorname{Ins}(1,4,5) \mathrm{P}_{3}$ at the 2-position (Fig. 1d,e; Supplementary Fig. 5). Finally, our IP6K structure provides the missing template necessary for the rational design of inhibitors that might selectively target each of the 
different kinases that contain the PDKG motif, both for research tools and therapeutic applications.

\section{Methods \\ Protein expression and purification. In this study, we use EhIP6KA as an abbreviation for the E. histolytica IP6K with Genbank accession number} XP_648490.2, so as to distinguish it from two other gene products of that are also annotated as IP6Ks. A previous study ${ }^{20}$ named this enzyme as EhIPK1. A codonoptimized cDNA for expression in Escherichia coli of EhIP6KA was synthesized by Genscript 5'-ATGAACACGAAAATCAAACGCGAACACATGAGTACGAAGAA AAGCCAATGGGTCCAAGCAGGTGGTCACGGTGGTCCGCAACAACTGCAT CCGGATGGCCAGTACCTGCTGAAACCGTGCCTGTCCCATCGTGAACGCG ACTTTTATCTGCACATTAAAGATGACAAGGAATGGACCGGCACGGGTA TTATCCCGAAATTCTACGGCGTCGAACTGCACGAATTTGGCTTCGGTGA ACTGGAATTTATCCGTATGGAAAACCTGATGTACAAATACAAGCGCC CGTTCGTTCTGGATCTGAAAATCGGCACCCAAACGTGGGACCCGGAA ACCGCGAGCAGCAAAATGAAAAAGCGTCTGGTGGTTGATTCGACCAGCA CCACGACCTCTCTGGGCGTGCGTTTTAGTGGTATGGAACGCAATATTG GCGAAGAAAAACCGATCCTGTATTCGCGTTACCTGTGTACCCATGAAG TTAACACGCGCGATAGCCTGAAGGAATACATCAAGCTGTTTTTCAACGA CGGTAAAAAGTACCGTAAGGAACTGGTTCCGTACTTTATTAGCCAGCT GGATAAAATGATCGAAGTCATGAAAAAGCGCGAATATAAGATGTTT AGTTCCTCAGTCCTGTTCGTGTACGATTCTACGACCACGCTGGAAGACA AGAAGTACAACTGCAAGATGATCGATTTCGCCCACAATTGGATTCTGTC AGAAGAAGAATGTACCGTGGAAGATGGCTTTCTGTTCGGTCTGAACA ATCTGAAATCCATTCTGGAAGACATCGAAAACGAATTTAAGTCACT GTAA- $3^{\prime}$.

The Gateway Expression System (Invitrogen) was used to subclone EhIP6KA into the pDest-566 vector. This vector encodes a $6 \times$ His tag, a maltose-binding protein tag and TEV protease cleavage site at the $\mathrm{N}$ terminus. ArcticExpress (DE3)competent cells (Stratagene) were transformed with the resultant plasmid. An overnight culture of E. coli cells carrying the pDest-566-EhIP6KA was inoculated into $2 \times$ yeast extract tryptone medium at $\mathrm{pH} 7.5$ and grown at $37^{\circ} \mathrm{C}$ to $A_{595}=0.7$. Isopropyl $\beta$-D-thiogalactopyranoside $(0.1 \mathrm{mM})$ was then added and cultures were continued at $15^{\circ} \mathrm{C}$ for 1 day. The cells were disrupted (Constant Systems) at $20 \mathrm{kPsi}$. Recombinant EhIP6KA proteins were purified with a Ni-NTA agarose column (Qiagen) followed by a HiTrap Q FF column (GE Healthcare). The bound proteins were released by TEV protease in the presence of $20 \mathrm{mM}$ Tris- $\mathrm{HCl}$ (pH 7.5), $50 \mathrm{mM} \mathrm{NaCl}, 1.5 \mathrm{mM}$ DTT, $10 \mathrm{mM} \mathrm{ATP}, 20 \mathrm{mM} \mathrm{MgCl}_{2}$, then applied to a HiTrap Q FF column. In the case of the MBP fusion protein, this TEV cleavage step was omitted. As a final step, a Superdex 200 gel filtration column (GE Healthcare) was used with a running buffer of $50 \mathrm{mM} \mathrm{NaCl}$ and $20 \mathrm{mM}$ Tris- $\mathrm{HCl}, \mathrm{pH} 7.5$.

Human IP6K2 cDNA was ordered from American Type Culture Collection (I.M.A.G.E. Clone ID 6162048, ATCC number 10437631). The Gateway expression system (Invitrogen) was used to subclone the kinase into the pDest-566 vector. Lemo21(DE3)-competent E. coli cells (New England Biolabs) were transformed with the resultant plasmid. An overnight culture of $E$. coli cells carrying the pDest$566-H s I P 6 \mathrm{~K} 2$ was inoculated into $2 \times$ yeast extract tryptone medium supplemented with $0.6 \mathrm{mM}$ L-rhamnose at $\mathrm{pH} 7.5$ and grown at $37^{\circ} \mathrm{C}$ to $A_{595}=0.7$. Isopropyl $\beta$-D-thiogalactopyranoside $(0.1 \mathrm{mM})$ was then added and cultures were continued at $14^{\circ} \mathrm{C}$ for 2 days. The cells were disrupted using a constant cell disruption system (Constant Systems) under $20 \mathrm{kPsi}$. Recombinant HsIP6K2 was purified with a Ni-NTA agarose column (Qiagen) followed by a HiTrap Heparin HP column (GE Healthcare), TEV protease cleavage and a HiTrap Q FF column (GE Healthcare). As a final step, a Superdex 200 gel filtration column (GE Healthcare) was used with a running buffer of $150 \mathrm{mM} \mathrm{NaCl}$ and $20 \mathrm{mM}$ Tris- $\mathrm{HCl}$, $\mathrm{pH}$ 7.5. Mutant proteins were purified similarly. For site-directed mutagenesis, the $5^{\prime}$ version of the complementary primers was as follows (mutagenic nucleotides are emphasized):

K222A, 5'-GGTGCCTTGTGTCCTTGACCTCGCGATGGGCACACGA CAACATGGTG-3'

K236A, 5'-CAACATGGTGATGATGCTTCAGAGGAGGCGGCAGCCAAC CAGATCCGAAAATG-3'

Q240M, 5'-CTTCAGAGGAGAAGGCAGCCAACATGATCCGAAAAT

GTCAGCAGAGCACATC-3'

N239YQ240M, 5'-GCTTCAGAGGAGAAGGCAGCCTACATGATCCGAAA ATGTCAGCAGAGCACATC- $3^{\prime}$

R242A, 5'-GGAGAAGGCAGCCAACCAGATCGCAAAATGTCAGC AGAGCACATCTGCAG- $3^{\prime}$

K243A, 5'-GAAGGCAGCCAACCAGATCCGAGCATGTCAGCAGAGCA CATCTGCAGTC- $3^{\prime}$

K273A, 5'-GTGGGCAGCTCATGTTCATGAACGCGTACCATGGAC

GGAAGCTATCGG-3'

Y274A, 5'-GGGCAGCTCATGTTCATGAACAAGGCCCATGG

ACGGAAGCTATCGGTG-3'

C257E, 5'-GTCATTGGTGTGCGTGTGGAGGGCATGCAGGTGTACCA AG-3'

R278A, 5'-GTTCATGAACAAGTACCATGGAGCGAAGCTATCGGTGC $\mathrm{AG}-3^{\prime}$
Recombinant DIPP1 was expressed and purified as previously described ${ }^{46}$ with an additional, heparin-affinity purification step. The purity of all proteins was estimated to be $>95 \%$ as judged by SDS-polyacrylamide gel electrophoresis. The purified proteins were concentrated and stored at $-80^{\circ} \mathrm{C}$.

Sample preparation for NMR analysis. Full length EhIP6KA (1-3 mg) was incubated in $3 \mathrm{ml}$ medium containing $150 \mathrm{mM} \mathrm{NaCl}, 20 \mathrm{mM}$ Tris- $\mathrm{HCl}$ (pH 7.0), $2 \mathrm{mM} \mathrm{MgCl}_{2}, 3 \mathrm{mM}$ ATP and $3 \mathrm{mM} \mathrm{InsP}_{6}$ at $37^{\circ} \mathrm{C}$ for 1 day and then $25^{\circ} \mathrm{C}$ for 3 days. The reaction sample was centrifuged and filtered to remove protein, and then vacuum dried at $45^{\circ} \mathrm{C}$ for $30 \mathrm{~min}$.

The sample was prepared by taking up the reaction mixture in $\mathrm{D}_{2} \mathrm{O}$ to a volume of $600 \mu \mathrm{l}$ and adjusting the $\mathrm{pH}$ to 6.2 using $\mathrm{NaOH}$ and $\mathrm{HCl}$. In addition, sodium CDTA was added to a concentration of $20 \mathrm{mM}$ to alleviate broadening of the ${ }^{31} \mathrm{P}$ resonances due to chemical exchange of the phosphate groups with the high concentration of $\mathrm{Mg}^{2+}$ in the sample. All ${ }^{1} \mathrm{H}$ and ${ }^{31} \mathrm{P}$ chemical shifts were referenced to $\sim 5 \mu \mathrm{M}$ internal DSS or to external $85 \%$ phosphoric acid, respectively. All NMR experiments were carried out at $25^{\circ} \mathrm{C}$ using a Varian Inova $600 \mathrm{MHz}$ NMR spectrometers, equipped with either a $5 \mathrm{~mm}$ broad band NMR probe tuned to ${ }^{31} \mathrm{P}$ on the observe channel and ${ }^{1} \mathrm{H}$ on the decoupler channel, or a Varian $5 \mathrm{~mm}{ }^{1} \mathrm{H}\left\{{ }^{15} \mathrm{~N},{ }^{13} \mathrm{C}\right\}$ Cold Probe (Agilent, Santa Clara CA). The $1 \mathrm{D}{ }^{1} \mathrm{H}$ spectra were acquired with sweep widths of 12 p.p.m., with an acquisition time of $1 \mathrm{~s}$, using a 1-s relaxation delay and with presaturation of the residual water resonance during the relaxation delay. The $1 \mathrm{D}^{31} \mathrm{P}$ spectrum was obtained using a 50 p.p.m. sweep width, with an acquisition time of $1.6 \mathrm{~s}$, using a 1-s relaxation delay and with ${ }^{1} \mathrm{H}$ decoupling during acquisition. The $2 \mathrm{D}{ }^{1} \mathrm{H}-{ }^{31} \mathrm{P}$ HSQC spectrum was acquired with sweep widths of 12 p.p.m. and 25 p.p.m. in the ${ }^{1} \mathrm{H}$ and ${ }^{31} \mathrm{P}$ dimensions, respectively, with $142.3 \mathrm{~ms}$ and $42 \mathrm{~ms}$ acquisition times in these dimensions and with ${ }^{1} \mathrm{H}$ decoupling during the acquisition. The $1 / 4 \mathrm{~J}$ delay in the HSQC experiment was set to $31.25 \mathrm{~ms}$, corresponding to a ${ }^{1} \mathrm{H}-{ }^{31} \mathrm{P}$ scalar coupling of $8 \mathrm{~Hz}$. The ${ }^{1} \mathrm{H}-{ }^{1} \mathrm{H}$ and ${ }^{31} \mathrm{P}-{ }^{31} \mathrm{P}$ COSY spectra were acquired using gradientselected absolute value mode COSY experiments. The proton COSY experiment was acquired using 12 p.p.m. sweep widths in both dimensions, with acquisition times of $342 \mathrm{~ms}$ and $71 \mathrm{~ms}$ in the directly and indirectly detected dimensions, respectively, and with a 1-s relaxation delay, during which time, presaturation of the residual water signal was applied. The phosphorus COSY experiment was acquired using 25 p.p.m. sweep widths in both dimensions, with acquisition times of $512 \mathrm{~ms}$ and $32 \mathrm{~ms}$ in the directly and indirectly detected dimensions, respectively, and with a $1-\mathrm{s}$ relaxation delay. The ${ }^{31} \mathrm{P}-{ }^{31} \mathrm{P}$ COSY spectrum was also acquired with ${ }^{1} \mathrm{H}$ decoupling in both dimensions. All spectra were processed using Varian VnmrJ 2.2D software (Agilent) on the Varian Inova spectrometer.

Enzyme assays and HPLC analysis. Kinase assays were performed by incubating enzyme preparations with either $\left[{ }^{3} \mathrm{H}\right] \operatorname{Ins}(1,4,5) \mathrm{P}_{3}$ (American Radiolabeled Chemicals, Saint Louis, MO), $\left[{ }^{14} \mathrm{C}\right]-\operatorname{Ins}(1,3,4,5,6) \mathrm{P}_{5}$ (isolated from $\left[{ }^{14} \mathrm{C}\right]$-labelled parotid acinar cells ${ }^{47}$ ) or $\left[{ }^{3} \mathrm{H}\right] \mathrm{InsP}_{6}$ (Perkin-Elmer Waltham MA) at $37^{\circ} \mathrm{C}$ in buffer containing $150 \mathrm{mM} \mathrm{KCl}, 20 \mathrm{mM}$ HEPES pH 7.0, $12 \mathrm{mM} \mathrm{MgSO}_{4}, 10 \mathrm{mM}$ ATP, $1 \mathrm{mM}$ EDTA. After either $20 \mathrm{~min}$ (InsP $\mathrm{P}_{6}$ phosphorylation) or $0.5-7 \mathrm{~h}\left(\operatorname{Ins}(1,4,5) \mathrm{P}_{3}\right.$ phosphorylation) reactions were acid quenched and neutralized ${ }^{48}$, and analysed by HPLC using either a $4.6 \times 125 \mathrm{~mm}$ Partisphere $5 \mu \mathrm{m}$ SAX column or a Q100 SAX column. The Partisphere column was eluted with one of two ammonium phosphate elution protocols: Gradient 1 (ref. 48) or Gradient 2 (ref. 49). The Q100 column was eluted with a gradient generated from Buffer A (1 mM Na2EDTA) and Buffer B (Buffer A plus $2 \mathrm{M} \mathrm{NH}_{4} \mathrm{H}_{2} \mathrm{PO}_{4} \mathrm{pH} 3.9$ with $\mathrm{H}_{3} \mathrm{PO}_{4}$ ) in the following manner: 0-5 min, 0\% B; 5-100 min, 0-42\% B, 110-140 min, 42-70\% B (Gradien 3). Radioactivity was measured either with an in-line counter, or after collecting $1 \mathrm{ml}$ or $0.5 \mathrm{ml}$ fractions. Other radiolabelled InsPs used for HPLC standards included $\left[{ }^{3} \mathrm{H}\right] \operatorname{Ins}(1,2,4,5) \mathrm{P}_{4}$ (prepared by heating $\left[{ }^{3} \mathrm{H}\right] \operatorname{Ins}(1,3,4,5) \mathrm{P}_{4}$ in $0.5 \mathrm{ml} 1 \mathrm{M}$ $\mathrm{HCl}$ at $90{ }^{\circ} \mathrm{C}$ for $\left.20 \mathrm{~min}^{50}\right),\left[{ }^{14} \mathrm{C}\right]-\operatorname{Ins}(1,3,4,5) \mathrm{P}_{4}$ and $\left[{ }^{14} \mathrm{C}\right]-\operatorname{Ins}(1,4,5,6) \mathrm{P}_{4}$ (isolated from carbachol-stimulated, $\left[{ }^{14} \mathrm{C}\right]$-labelled parotid acinar cells $\left.{ }^{47}\right), \mathrm{PP}-\left[{ }^{3} \mathrm{H}\right] \mathrm{InsP}_{4}$ and $[\mathrm{PP}]_{2}-\left[{ }^{3} \mathrm{H}\right] \mathrm{InsP}_{3}$ (both prepared by hIP6K2-mediated phosphorylation of $\left[{ }^{3} \mathrm{H}\right]-$ Ins $\left.(1,3,4,5,6) \mathrm{P}_{5}{ }^{36}\right)$. Data for the kinase assays are presented as mean values \pm s.e.

Crystallization. The MBP fusion protein of EhIP6KA (residues 32-270) was crystallized by hanging drop vapour diffusion against a well buffer of $12 \%(\mathrm{w} / \mathrm{v})$ PEG 3350, $50 \mathrm{mM} \mathrm{NaH}{ }_{2} \mathrm{PO}_{4}$, pH 5.5 at $18^{\circ} \mathrm{C}$. The protein concentration was $>60 \mathrm{mg} \mathrm{ml}^{-1}$. The core catalytic domain of EhIP6KA (residues 20-270) was crystallized by hanging drop vapour diffusion for 1 week against a well buffer of $8 \%$ (w/v) PEG 3350, $100 \mathrm{mM} \mathrm{Na}{ }_{3}$ Citrate, $\mathrm{pH} 5.2$ at $25^{\circ} \mathrm{C}$, followed by dilution microseeding (Seed Bead kit, Hampton Research) for 2 weeks with a well buffer of $8 \%(\mathrm{w} / \mathrm{v})$ PEG 3,350, $100 \mathrm{mM} \mathrm{Na}{ }_{3}$ Citrate, $\mathrm{pH} 5.2,8 \%$ ethylene glycol at $25^{\circ} \mathrm{C}$. The crystals were displayed as a thin plate and were anisotropic. Crystals of EhIP6KA (residues 27-270) emerged under $0.4 \mathrm{M} \mathrm{NaH}_{2} \mathrm{PO}_{4}$ in the presence of $10 \mathrm{mM} \mathrm{ATP}$, plus either $10 \mathrm{mM} \mathrm{InsP}_{6}, 5 \mathrm{mM} \operatorname{Ins}(1,3,4,5,6) \mathrm{P}_{5}$ or $5 \mathrm{mM} \mathrm{Ins}(1,4,5) \mathrm{P}_{3} / 20 \mathrm{mM}$ $\mathrm{MgCl}_{2}$. To increase occupancy of InsPs and remove the effect of phosphate ions, the crystals were further soaked under $22 \%$ (w/v) PEG 3350, $10 \mathrm{mM} \mathrm{MgCl}_{2}, 10 \mathrm{mM}$ ATP, $0.1 \mathrm{M}$ sodium acetate, $\mathrm{pH} 5.2$ and $20 \mathrm{mM}$ InsP, $10 \mathrm{mM} \operatorname{Ins}(1,3,4,5,6) \mathrm{P}_{5}$ or $10 \mathrm{mM}$ Ins $(1,4,5) \mathrm{P}_{3}$ for 3 days. Cryosolvent was prepared by adding $33 \%$ ethylene glycol into the soaking buffer. 
Data collection and structure determination. Diffraction data were collected using APS beamlines 22-ID and 22-BM. All data were processed with the programme HKL2000 (ref. 51). Initial phases for the structure of MBP-EhIPK1 were determined by molecular replacement using MBP (1ez9) and HsIP3KA (1w2c) as searching models. Then the first structure was manually rebuilt with COOT $^{52}$ and refined with REFMAC from the CCP4 package ${ }^{53}$. The other crystal structures were determined either by molecular replacement if the space group was different, or by using rigid body and direct Fourier synthesis, and refined with the equivalent and expanded test sets. A Cartesian-simulated annealing protocol was performed in the first round of refinement. Ligand topology and parameter files were prepared using the incorporated PRODRG programme from the CCP4 package ${ }^{53}$. The molecular graphics representations were prepared with the programme PyMol (Schrödinger, LLC)

\section{References}

1. Shears, S. B. Diphosphoinositol polyphosphates: metabolic messengers? Mol. Pharmacol. 76, 236-252 (2009).

2. Wilson, M. S., Livermore, T. M. \& Saiardi, A. Inositol pyrophosphates: between signalling and metabolism. Biochem. J. 452, 369-379 (2013).

3. Szijgyarto, Z., Garedew, A., Azevedo, C. \& Saiardi, A. Influence of inositol pyrophosphates on cellular energy dynamics. Science 334, 802-805 (2011).

4. Illies, C. et al. Inositol pyrophosphates determine exocytic capacity. Science 318, 1299-1302 (2007)

5. Chakraborty, A. et al. Inositol pyrophosphates inhibit AKT signaling, thereby regulating insulin sensitivity and weight gain. Cell 143, 897-910 (2010).

6. Lee, Y. S., Mulugu, S., York, J. D. \& O'Shea, E. K. Regulation of a cyclin-CDKCDK inhibitor complex by inositol pyrophosphates. Science 316, 109-112 (2007).

7. Gokhale, N. A., Zaremba, A., Janoshazi, A. K., Weaver, J. D. \& Shears, S. B. PPIP5K1 modulates ligand competition between diphosphoinositol polyphosphates and PtdIns(3,4,5)P3 for polyphosphoinositide-binding domains. Biochem. J. 453, 413-426 (2013).

8. Pulloor, N. K. et al. Human genome-wide RNAi screen identifies an essential role for inositol pyrophosphates in type-I interferon response. PLoS Pathog. 10, e1003981 (2014)

9. Bennett, M., Onnebo, S. M., Azevedo, C. \& Saiardi, A. Inositol pyrophosphates: metabolism and signaling. Cell. Mol. Life Sci. 63, 552-564 (2006).

10. Saiardi, A., Erdjument-Bromage, H., Snowman, A., Tempst, P. \& Snyder, S. H. Synthesis of diphosphoinositol pentakisphosphate by a newly identified family of higher inositol polyphosphate kinases. Curr. Biol. 9, 1323-1326 (1999).

11. Saiardi, A., Nagata, E., Luo, H. R., Snowman, A. M. \& Snyder, S. H. Identification and characterization of a novel inositol hexakisphosphate kinase. J. Biol. Chem. 276, 39179-39185 (2001).

12. Draskovic, P. et al. Inositol hexakisphosphate kinase products contain diphosphate and triphosphate groups. Chem. Biol. 15, 274-286 (2008)

13. Lin, H. et al. Structural analysis and detection of biological inositol pyrophosphates reveals that the VIP/PPIP5K family are 1/3-kinases. J. Biol. Chem. 284, 1863-1872 (2009).

14. Bhandari, R., Juluri, K. R., Resnick, A. C. \& Snyder, S. H. Gene deletion of inositol hexakisphosphate kinase 1 reveals inositol pyrophosphate regulation of insulin secretion, growth, and spermiogenesis. Proc. Natl Acad. Sci. USA 105, 2349-2353 (2008).

15. Ghosh, S. et al. Inositol hexakisphosphate kinase 1 maintains hemostasis in mice by regulating platelet polyphosphate levels. Blood 122, 1478-1486 (2013).

16. Jadav, R. S., Chanduri, M. V., Sengupta, S. \& Bhandari, R. Inositol pyrophosphate synthesis by inositol hexakisphosphate kinase 1 is required for homologous recombination repair. J. Biol. Chem. 288, 3312-3321 (2012).

17. Burton, A., Azevedo, C., Andreassi, C., Riccio, A. \& Saiardi, A. Inositol pyrophosphates regulate JMJD2C-dependent histone demethylation. Proc. Natl Acad. Sci. USA 110, 18970-18975 (2013).

18. Morrison, B. H., Bauer, J. A., Kalvakolanu, D. V. \& Lindner, D. J. Inositol hexakisphosphate kinase 2 mediates growth suppressive and apoptotic effects of interferon-b in ovarian carcinoma cells. J. Biol. Chem. 276, 24965-24970 (2001).

19. Morrison, B. H. et al. Gene deletion of inositol hexakisphosphate kinase 2 predisposes to aerodigestive tract carcinoma. Oncogene 28, 2383-2392 (2009).

20. Loser, B. et al. A novel Entamoeba histolytica inositol phosphate kinase catalyzes the formation of 5PP-Ins(1,2,3,4,6)P(5). Mol. Biochem. Parasitol. 181, 49-52 (2012).

21. Odom, A. R., Stahlberg, A., Wente, S. R. \& York, J. D. A role for nuclear inositol 1,4,5-trisphosphate kinase in transcriptional control. Science 287, 2026-2029 (2000).

22. Saiardi, A., Caffrey, J. J., Snyder, S. H. \& Shears, S. B. Inositol polyphosphate multikinase (ArgRIII) determines nuclear mRNA export in Saccharomyces cerevisiae. FEBS Lett. 468, 28-32 (2000).

23. Chang, S.-C., Miller, A. L., Feng, Y., Wente, S. R. \& Majerus, P. W. The human homologue of the rat inositol phosphate multikinase is an inositol 1,3,4,6tetrakisphosphate 5-kinase. J. Biol. Chem. 277, 43836-43843 (2002).
24. Yang, X. \& Shears, S. B. Multitasking in signal transduction by a promiscuous human Ins(3,4,5,6)P4 1-Kinase/Ins(1,3,4)P3 5/6-Kinase. Biochem. J. 351, $551-555$ (2000).

25. Shears, S. B. How versatile are inositol phosphate kinases? Biochem. J. 377, 265-280 (2004).

26. Holmes, W. \& Jogl, G. Crystal structure of inositol phosphate multikinase 2 and implications for substrate specificity. J. Biol. Chem. 281, 38109-38116 (2006).

27. Miller, G. J., Wilson, M. P., Majerus, P. W. \& Hurley, J. H. Specificity determinants in inositol polyphosphate synthesis: crystal structure of inositol 1,3,4-trisphosphate 5/6-kinase. Mol. Cell 18, 201-212 (2005).

28. Endo-Streeter, S., Tsui, M. K., Odom, A. R., Block, J. \& York, J. D. Structural studies and protein engineering of inositol phosphate multikinase. J. Biol. Chem. 287, 35360-35369 (2012).

29. Chamberlain, P. P. et al. Integration of inositol phosphate signaling pathways via human ITPK1. J. Biol. Chem. 282, 28117-28125 (2007).

30. Khersonsky, O. \& Tawfik, D. S. Enzyme promiscuity: a mechanistic and evolutionary perspective. Annu. Rev. Biochem. 79, 471-505 (2010).

31. Miller, G. J. \& Hurley, J. H. Crystal structure of the catalytic core of inositol 1,4,5-trisphosphate 3-kinase. Mol. Cell. 15, 703-711 (2004).

32. Gonzalez, B. et al. Structure of a human inositol 1,4,5-trisphosphate 3-kinase; substrate binding reveals why it is not a phosphoinositide 3-kinase. Mol. Cell 15, 689-701 (2004).

33. Albert, C. et al. Biological variability in the structures of diphosphoinositol polyphosphates in Dictyostelium discoideum and mammalian cells. Biochem. J. 327, 553-560 (1997).

34. Kilari, R. S., Weaver, J. D., Shears, S. B. \& Safrany, S. T. Understanding inositol pyrophosphate metabolism and function: kinetic characterization of the DIPPs. FEBS Lett. 587, 3464-3470 (2013).

35. Barker, C. J., Illies, C., Gaboardi, G. C. \& Berggren, P. O. Inositol pyrophosphates: structure, enzymology and function. Cell. Mol. Life Sci. 66, 3851-3871 (2009).

36. Saiardi, A., Caffrey, J. J., Snyder, S. H. \& Shears, S. B. The inositol hexakisphosphate kinase family: catalytic flexibility, and function in yeast vacuole biogenesis. J. Biol. Chem. 275, 24686-24692 (2000).

37. Verbsky, J. W., Wilson, M. P., Kisseleva, M. V., Majerus, P. W. \& Wente, S. R. The synthesis of inositol hexakisphosphate: characterization of human inositol 1,3,4,5,6-pentakisphosphate 2-kinase. J. Biol. Chem. 277, 31857-31862 (2002)

38. Safrany, S. T. et al. A novel context for the 'MutT' module, a guardian of cell integrity, in a diphosphoinositol polyphosphate phosphohydrolase. EMBO J. 17, 6599-6607 (1998).

39. Vieira-Pires, R. S. \& Morais-Cabral, J. H. 3(10) helices in channels and other membrane proteins. J. Gen. Physiol. 136, 585-592 (2010).

40. Pal, L. \& Basu, G. Novel protein structural motifs containing two-turn and longer 3(10)-helices. Protein Eng. 12, 811-814 (1999).

41. Padmanabhan, U., Dollins, D. E., Fridy, P. C., York, J. D. \& Downes, C. P. Characterization of a selective inhibitor of inositol hexakisphosphate kinases: Use in defining biological roles and metabolic relationships of inositol pyrophosphates. J. Biol. Chem. 284, 10571-10582 (2009).

42. Mildvan, A. S. Mechanisms of signaling and related enzymes. Proteins 29, 401-416 (1997).

43. Nagata, E. et al. Inositol hexakisphosphate kinase-2, a physiologic mediator of cell death. J. Biol. Chem. 280, 1634-1640 (2005).

44. Gonzalez, B., Banos-Sanz, J. I., Villate, M., Brearley, C. A. \& Sanz-Aparicio, J. Inositol 1,3,4,5,6-pentakisphosphate 2-kinase is a distant IPK member with a singular inositide binding site for axial 2-OH recognition. Proc. Natl Acad. Sci. USA 107, 9608-9613 (2010).

45. Wang, H., Falck, J. R., Hall, T. M. \& Shears, S. B. Structural basis for an inositol pyrophosphate kinase surmounting phosphate crowding. Nat. Chem. Biol. 8, 111-116 (2012).

46. Yang, X., Safrany, S. T. \& Shears, S. B. Site-directed mutagenesis of DIPP, a dual specificity MutT/Nudix-type hydrolase that attacks diadenosine polyphosphates and diphosphoinositol polyphosphates. J. Biol. Chem. 274, 35434-35440 (1999).

47. McConnell, F. M., Stephens, L. R. \& Shears, S. B. Multiple isomers of inositol pentakisphosphate in Epstein-Barr-virus-transformed (T5-1) B-lymphocytes. Identification of inositol 1,3,4,5,6-pentakisphosphate, D-inositol 1,2,4,5,6pentakisphosphate and L-inositol 1,2,4,5,6-pentakisphosphate. Biochem. J. 280, 323-329 (1991).

48. Weaver, J. D., Wang, H. \& Shears, S. B. The kinetic properties of a human PPIP5K reveal that its kinase activities are protected against the consequences of a deteriorating cellular bioenergetic environment. Biosci. Rep. 33, 228-241 (2013).

49. Safrany, S. T. \& Shears, S. B. Turnover of bis-diphosphoinositol tetrakisphosphate in a smooth muscle cell line is regulated by $\mathrm{b}_{2}$ - adrenergic receptors through a cAMP-mediated, A-kinase-independent mechanism. EMBO J. 17, 1710-1716 (1998).

50. Brearley, C. A. \& Hanke, D. E. Metabolic evidence for the order of addition of individual phosphate esters to the myo-inositol moiety of inositol 
hexakisphosphate in the duckweed Spirodela polrhiza L. Biochem. J. 314, 227-233 (1996).

51. Otwinowski, Z. \& Minor, W. Processing of X-ray diffraction data collected in oscillation mode. Methods Enzymol. 276, 307-326 (1997).

52. Emsley, P. \& Cowtan, K. Coot: model-building tools for molecular graphics. Acta Crystallogr. D Biol. Crystallogr. 60, 2126-2132 (2004).

53. Winn, M. D., Murshudov, G. N. \& Papiz, M. Z. Macromolecular TLS refinement in REFMAC at moderate resolutions. Methods Enzymol. 374, 300-321 (2003).

54. Chakraborty, A. et al. HSP90 regulates cell survival via inositol hexakisphosphate kinase-2. Proc. Natl Acad. Sci. USA 105, 1134-1139 (2008).

55. Chakraborty, A. et al. Casein kinase-2 mediates cell survival through phosphorylation and degradation of inositol hexakisphosphate kinase-2. Proc. Natl Acad. Sci. USA 108, 2205-2209 (2011).

\section{Acknowledgements}

This research was supported by the Intramural Research Programme of the NIH, National Institute of Environmental Health Sciences. We thank T.M. Hall and L.C. Pedersen for discussions and critical reading of the manuscript, the NIEHS Collaborative crystallography group, the Advanced Photon Source (APS) Southeast Regional Collaborative Access Team (SER-CAT) 22-ID and 22-BM beam lines for assistance with crystallographic data collection.

\section{Author contributions}

H.W., E.F.D. and S.B.S. performed experiments. All authors designed experiments and wrote the paper.

\section{Additional information}

Accession codes: Atomic coordinates and structure factors have been deposited in the Protein Data Bank with accession codes: 4O4B, EhIP6KA (residues 32-270) tagged with maltose-binding protein at the $\mathrm{N}$ terminus; $4 \mathrm{O} 4 \mathrm{C}$, apo-EhIP6KA (residues 20-270); 4O4D, EhIP6KA (residues 27-270) in complex with ATP and Ins $(1,4,5) \mathrm{P}_{3} ; 4 \mathrm{O} 4 \mathrm{E}$, EhIP6KA (residues 27-270) in complex with ATP and Ins $(1,3,4,5,6) \mathrm{P}_{5} ; 4 \mathrm{O} 4 \mathrm{~F}$, EhIP6KA (residues 27-270) in complex with ATP and InsP $_{6}$.

Supplementary Information accompanies this paper at http://www.nature.com/ naturecommunications

Competing financial interests: The authors declare no competing financial interests.

Reprints and permission information is available online at http://npg.nature.com/ reprintsandpermissions/

How to cite this article: Wang, H. et al. IP6K structure and the molecular determinants of catalytic specificity in an inositol phosphate kinase family. Nat. Commun. 5:4178 doi: $10.1038 /$ ncomms5178 (2014). 